\title{
Radiative Impacts of Low-Level Clouds on the Summertime Subtropical High in the South Indian Ocean Simulated in a Coupled General Circulation $\operatorname{Model}^{\mathscr{a}}$
}

\author{
Ayumu Miyamoto, ${ }^{\mathrm{a}}$ Hisashi Nakamura,,${ }^{\mathrm{a}, \mathrm{b}}$ Takafumi Miyasaka, ${ }^{\mathrm{a}, \mathrm{c}}$ And Yu Kosaka ${ }^{\mathrm{a}}$ \\ ${ }^{a}$ Research Center for Advanced Science and Technology, The University of Tokyo, Tokyo, Japan \\ ${ }^{\mathrm{b}}$ Japan Agency for Marine-Earth Science and Technology, Yokohama, Japan \\ ${ }^{\mathrm{c}}$ Japan Meteorological Business Support Center, and Meteorological Research Institute, \\ Japan Meteorological Agency, Tsukuba, Japan
}

(Manuscript received 7 September 2020, in final form 5 February 2021)

\begin{abstract}
Over the south Indian Ocean, the coupled system of the subtropical Mascarene high and low-level clouds exhibits marked seasonality. To investigate this seasonality, the present study assesses radiative impacts of low-level clouds on the summertime Mascarene high with a coupled general circulation model. Comparison between a fully coupled control simulation and a "no-low-cloud simulation," where the radiative effects of low-level clouds are artificially turned off, demonstrates that they act to reinforce the Mascarene high. Their impacts are so significant that the summertime Mascarene high almost disappears in the no-low-cloud experiment, suggesting their essential role in the existence of the summertime Mascarene high. As the primary mechanism, lowered sea surface temperature by the cloud albedo effect suppresses deep convective precipitation, inducing a Matsuno-Gill type response that reinforces the high, as verified through an atmospheric dynamical model diagnosis. Associated reduction of high-top clouds, as well as increased low-level clouds, augments inatmosphere radiative cooling, which further reinforces the high. The present study reveals that low-level clouds constitute a tight positive feedback system with the subtropical high via sea surface temperature over the summertime south Indian Ocean.
\end{abstract}

KEYWORDS: Indian Ocean; Anticyclones; Atmosphere-ocean interaction; Clouds; Subtropics

\section{Introduction}

A surface subtropical high resides in each of the subtropical ocean basins, which can be regarded as the superposition of the zonal-mean Hadley circulation (e.g., Held and Hou 1980; Dima and Wallace 2003) and zonally asymmetric planetary waves (e.g., Rodwell and Hoskins 2001; Miyasaka and Nakamura 2005, 2010). A subtropical high not only influences climatic conditions over the surrounding regions but also drives an oceanic subtropical gyre, forming a warm western boundary current (e.g., the Kuroshio, Gulf Stream, or Agulhas Current) and a cool eastern boundary current (e.g., the Canary, California, Peru, or Benguela Currents). The equatorward winds over the eastern portion of a subtropical high induce coastal upwelling and upper-ocean mixing in addition to surface evaporation, acting to maintain relatively low sea surface temperature (SST) (e.g., Seager et al. 2003). The low SST under midtropospheric subsidence enhances lower-tropospheric static stability, favoring the formation of low-level clouds (e.g., Klein and Hartmann 1993; Wood and Bretherton 2006; Wood 2012;

¿ Denotes content that is immediately available upon publication as open access.

Supplemental information related to this paper is available at the Journals Online website: https://doi.org/10.1175/JCLI-D-200709.s1.

Corresponding author: Ayumu Miyamoto, ayumu@atmos.rcast. u-tokyo.ac.jp
Koshiro and Shiotani 2014; Miyamoto et al. 2018). Low-level clouds are important for Earth's radiation budget (e.g., Hartmann and Short 1980) and thus equilibrium climate sensitivity, which characterizes the degree of future global warming (e.g., Bony and Dufresne 2005; Qu et al. 2014, 2015; Myers and Norris 2016; Zelinka et al. 2020). Subtropical highs are therefore relevant in various contexts of climate science.

Previous studies focusing on the summertime (DJF and JJA for the Southern and Northern Hemispheres, respectively) subtropical highs suggested that local air-sea interaction is essential for their formation and maintenance. Using a planetary wave model that only solves time evolution of zonally asymmetric components, Rodwell and Hoskins (2001) argued that summertime monsoonal heating to the east of each surface subtropical high forces adiabatic descent and equatorward alongshore winds, enhancing local diabatic cooling to form the high. This is because equatorward wind acts to lower SST as described above, thereby suppressing deep convective heating and promoting radiative cooling with the associated midtropospheric subsidence. Seager et al. (2003) revealed the importance of the local air-sea interaction in obtaining the full strength of the subtropical highs in their model simulations. Miyasaka and Nakamura $(2005,2010)$ claimed the importance of lowertropospheric thermal contrast between the cool ocean under a subtropical high and the heated continent to the east under strong summertime insolation (Wu and Liu 2003). Using the same model as in Rodwell and Hoskins (2001), they argued that the near-surface cooling-heating couplets are more important than the remote monsoonal heating for the summertime subtropical highs.

Regarding the local air-sea interaction and associated maritime diabatic cooling, low-level clouds are considered to play an important role (e.g., Seager et al. 2003; Miyasaka and 
(a) DJF SLP* $\mid R A 55$

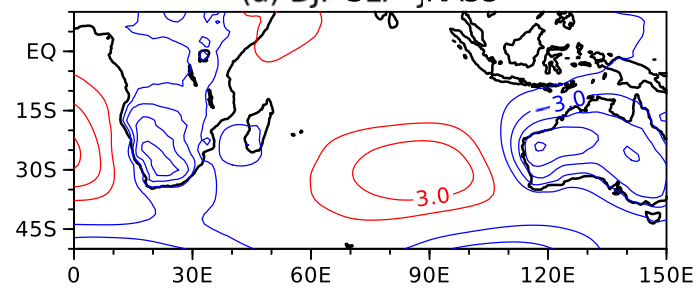

(b) MAM SLP* JRA55

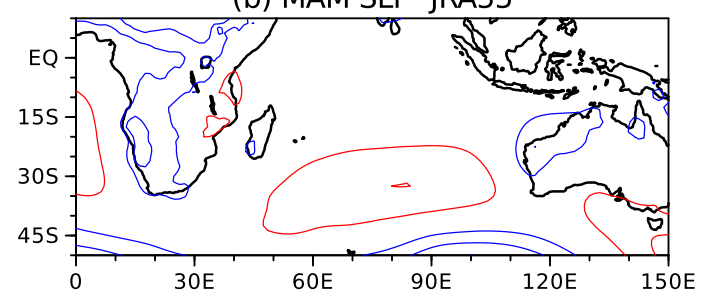

(c) JJA SLP* JRA55

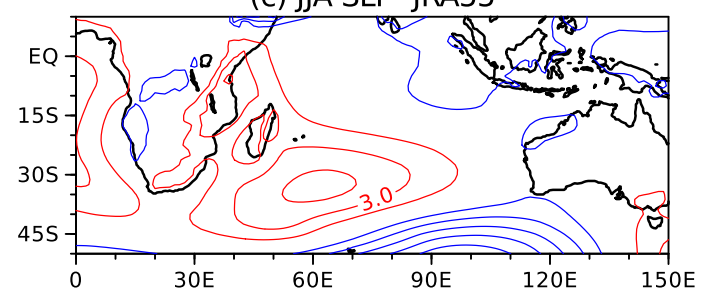

(d) SON SLP* JRA55

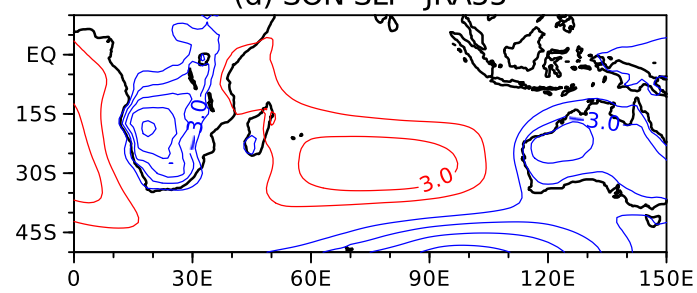

(e) DJF SLP* CM

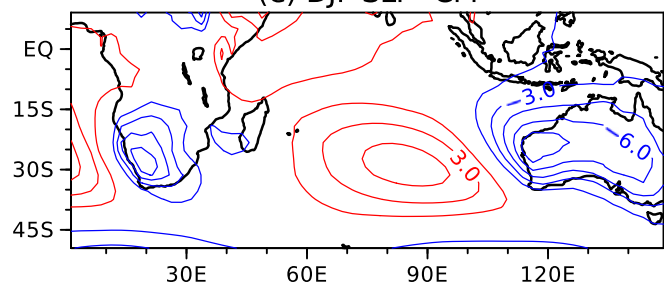

(f) MAM SLP* CM

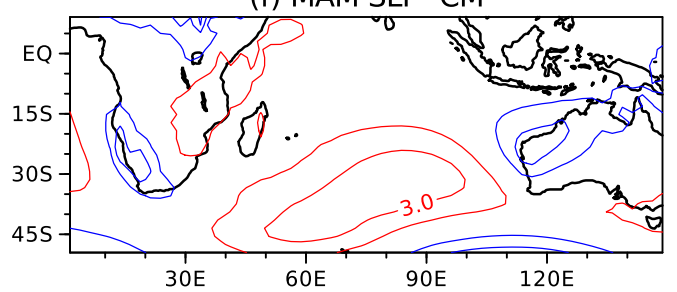

(g) JJA SLP* CM

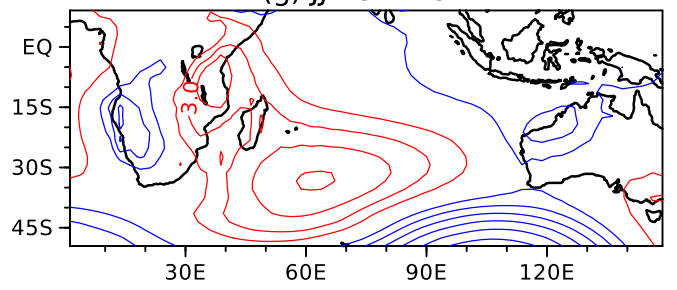

(h) SON SLP* CM

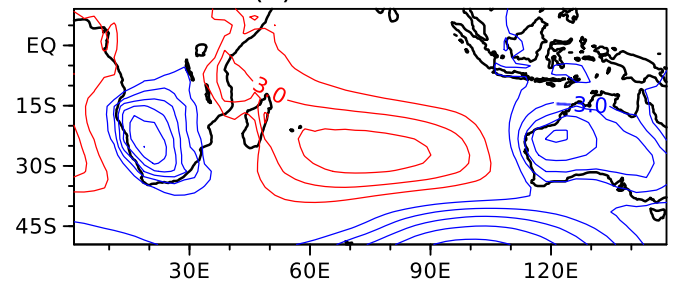

FIG. 1. Climatological distribution of zonally asymmetric SLP (contoured every $1.5 \mathrm{hPa}$ ) in austral (a) summer (DJF), (b) autumn (MAM), (c) winter (JJA), and (d) spring (SON) in JRA-55. Zero lines are omitted. (e)-(h) As in (a)-(d), respectively, but for the CM_CTL simulation.

Nakamura 2005, 2010). Low-level clouds not only lower SST owing to their high albedo but also enhance radiative cooling from their cloud top. In fact, Miyasaka and Nakamura (2005, 2010) attributed the maritime cooling, which explains most of the maritime high pressure response in their model, to cloudtop radiative cooling from low-level clouds, claiming the critical importance of low-level clouds on the maintenance of subtropical highs. Since subtropical highs promote the formation of low-level clouds, there must be a positive feedback between low-level clouds and a subtropical high.

Despite the importance of low-level clouds, few studies have assessed their feedback onto climatological-mean subtropical highs quantitatively and comprehensively. Several studies (e.g., Philander et al. 1996; Ma et al. 1996; Yu and Mechoso 1999; Gordon et al. 2000; Xie et al. 2007) investigated the climatological impacts of low-level clouds off the Peruvian coast. However, their focus was placed on the role of their albedo effect as a trigger of the equatorially asymmetric mode through the wind-evaporation-SST (WES) feedback (Xie and Philander 1994; Philander et al. 1996), and thereby their impacts on precipitation associated with the intertropical convergence zone (ITCZ). Thus, the atmospheric circulation system away from the equator has not been discussed thoroughly.

As in our earlier work (Miyamoto et al. 2018), the present study focuses on the south Indian Ocean (SIO), where the surface subtropical Mascarene high exhibits its distinct seasonality from its counterparts in other ocean basins (Figs. 1a-d; Rodwell and Hoskins 2001; Lee et al. 2013). As pointed out by Miyamoto et al. (2018), the Mascarene high resides over the eastern portion of the basin in summer (Fig. 1a) as in the other basins, but it strengthens and shifts westward in winter (Fig. 1c). The mechanisms for this unique seasonality, however, remain unsolved.

The present study investigates the coupling between the subtropical Mascarene high and low-level clouds in austral 
(a) DJF LCF CALIPSO

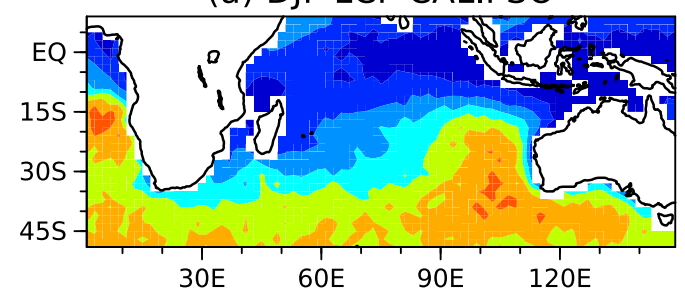

(b) MAM LCF CALIPSO

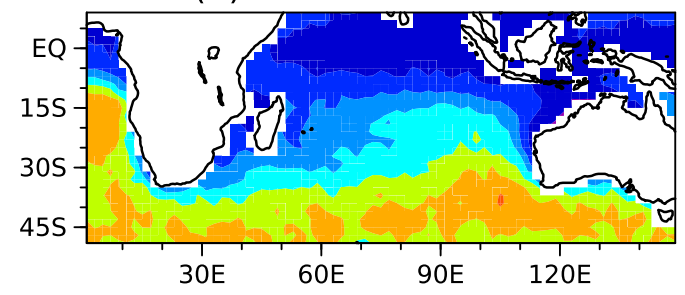

(c) JJA LCF CALIPSO

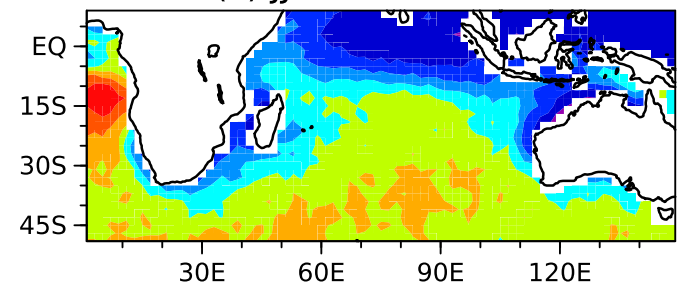

(d) SON LCF CALIPSO

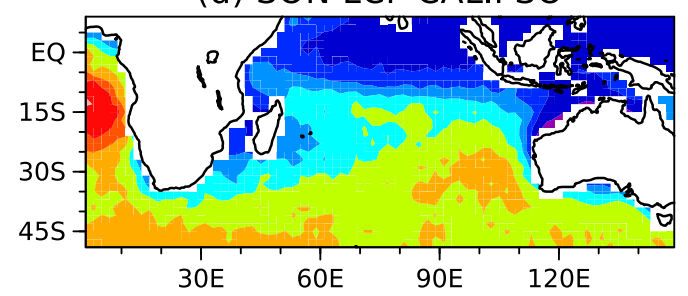

(e) DJF LCF CM

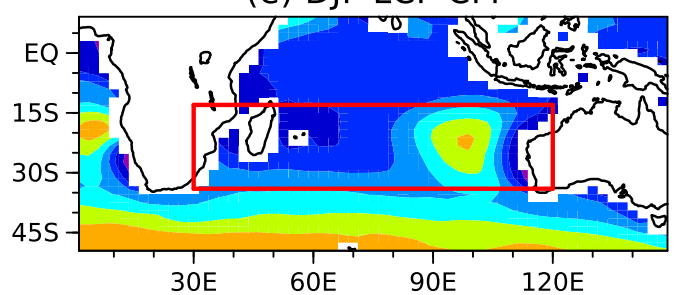

(f) MAM LCF CM

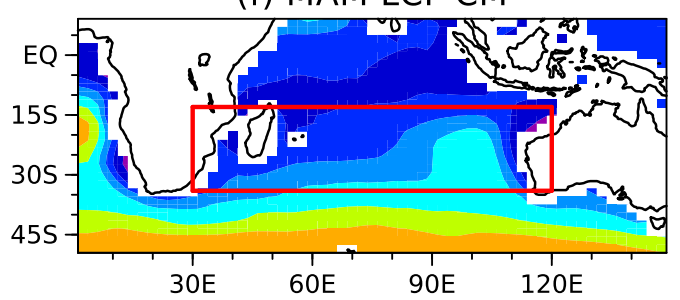

(g) JJA LCF CM

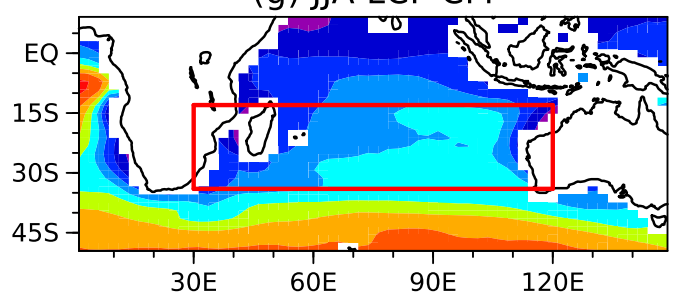

(h) SON LCF CM

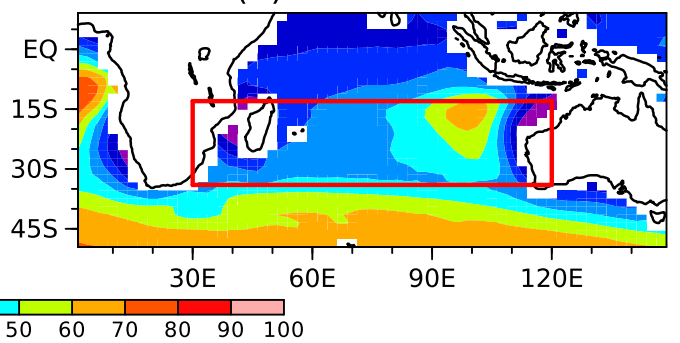

FIG. 2. Climatological distribution of maritime LCF (\%) in (a) DJF, (b) MAM, (c) JJA, and (d) SON in CALIPSO-GOCCP. (e)-(h) As in (a)-(d), respectively, but for the CM_CTL simulation. In (e)-(h), the red rectangular box indicates the domain where low-level clouds are made artificially transparent in the CM_NoCRE simulation. See the text for details. The coloring convention for all the panels is indicated at the bottom.

summer, when the high resides over the eastern portion of the ocean basin as in the other basins (e.g., Klein and Hartmann 1993; Miyamoto et al. 2018). Specifically, low-cloud fraction (LCF) is maximized off the west coast of Australia (Fig. 2a) in the eastern summertime Mascarene high centered over the eastern portion of the basin. We demonstrate a positive feedback from low-level clouds onto the summertime Mascarene high and reveal its mechanisms in a more quantitative manner than in previous studies. The wintertime feedback will be discussed in a future paper (Miyamoto et al. 2021, manuscript submitted to J. Climate).

We consider that the SIO is a geographical domain suited for quantifying feedback from low-level clouds on the subtropical high without any significant interference of the equatorial asymmetric mode generated through the WES feedback. Under the strong influence of the Asian monsoon, the climatological surface easterlies, which act as a necessary background condition for the occurrence of the WES feedback, blow over the equatorial Indian Ocean only in austral summer and early fall (e.g., Kawamura et al. 2001; Schott et al. 2009). In these seasons, the tropical westerlies on the northern side of the ITCZ located at $5^{\circ}-10^{\circ} \mathrm{S}$ hamper equatorward propagation of the coupled signal from the subtropical SIO.

The rest of the paper is organized as follows. Data and model descriptions are given in section 2 . In section 3 , the radiative impacts of low-level clouds on the summertime Mascarene high are assessed with a coupled general circulation model (CGCM), and the mechanisms are elucidated in detail with an atmospheric general circulation model (AGCM) and an atmospheric dynamical model. Specifically, section 3a discusses SST anomalies induced by low-level clouds (marked with the 
TABLE 1. Overview of the CGCM (top two rows) and AGCM (bottom three rows) experiments.

\begin{tabular}{lcc}
\hline \hline & $\begin{array}{c}\text { Radiative effects of low-level } \\
\text { clouds over the subtropical SIO }\end{array}$ & Prescribed SST \\
\hline CM_CTL & Active & - \\
CM_NoCRE & Inactive & Monthly climatology of CM_CTL \\
AM_CTL & Active & Monthly climatology of CM_CTL plus \\
AM_SSTAstSIO & Active & anomaly (defined as CM_NoCRE- \\
& & CM_CTL) over the subtropical SIO \\
AM_NoCRE_SSTclim & Inactive & Monthly climatology of CM_CTL \\
\hline
\end{tabular}

arrows from "Low-level clouds" and "Subtropical high" to "Subtropical SST" in Fig. 11a). After the reinforcement of the Mascarene high by the presence of low-level clouds in the CGCM experiments is demonstrated in section $3 b$, section $3 c$ discusses impacts of in-atmosphere radiative cooling from lowlevel clouds (marked with the direct arrow from "Low-level clouds" to "Subtropical high" in Fig. 11a). Section 3d demonstrates the reinforcement of the high by lowered SST through suppressing deep convection (marked with the arrow from "Subtropical SST" to "Subtropical high" in Fig. 11a). Section 4 provides a brief summary with additional discussions.

\section{Data and model experiments}

\section{a. Observational data}

This study uses the Japanese 55-year Reanalysis of the global atmosphere (JRA-55; Kobayashi et al. 2015; Harada et al. 2016) from 1979 through 2018. In addition to dynamical fields such as winds and temperature, individual contributions to diabatic heating from radiation $\left(Q_{\mathrm{rad}}\right)$, vertical diffusion $\left(Q_{\mathrm{vdf}}\right)$, and condensation (large-scale condensation plus cumulus convection; $Q_{\text {precip }}$ ) are available in JRA-55. To extract diabatic heating near the surface appropriately, we utilize model-level diabatic heating data rather than pressure-level data. It should be kept in mind that the diabatic heating is product of the forecast model used for JRA-55 and thus not strongly constrained by assimilated observational data.

We also use the GCM-Oriented CALIPSO (Cloud-Aerosol Lidar and Infrared Pathfinder Satellite Observations) Cloud Product (GOCCP) version 3 (Chepfer et al. 2010) for cloud fraction from June 2006 through May 2017, and the Clouds and the Earth's Radiant Energy System (CERES) Energy Balanced and Filled (EBAF) edition 4 (Loeb et al. 2018) for radiative fluxes at the top of the atmosphere (TOA) from March 2001 through February 2017.

\section{b. Coupled general circulation model}

This study uses the Geophysical Fluid Dynamics Laboratory (GFDL) Coupled Model version 2.1 (CM2.1; Delworth et al. 2006). In this CGCM, the horizontal resolution is $2^{\circ}$ latitude $\times$ $2.5^{\circ}$ longitude for the atmosphere and land. The atmospheric model has 24 levels in the vertical. The ocean model resolution is $1^{\circ}$ in both latitude and longitude over the extratropics, but the meridional resolution equatorward of $30^{\circ}$ becomes progressively finer to reach $1 / 3^{\circ}$ at the equator. There are 50 vertical levels in the ocean.

As a fully coupled control experiment (CM_CTL; Table 1), we integrate the model for 100 years with the radiative forcing fixed at the 1990 level. This study analyzes the last 50 years ending in November. Figure 2 compares the climatologicalmean LCF in CM_CTL with the satellite observations. CM_ CTL captures the important features of the seasonal cycle of LCF over the subtropical SIO, including its local maximum off the west coast of Australia in summer (Figs. 2a,e) and autumnto-winter enhancement of LCF in the central and western portions of the subtropical basin (Figs. 2b,c,f,g). However, CM_CTL overestimates LCF in spring (Figs. 2d,h) and its maximum is displaced equatorward compared to its observational counterpart. Otherwise, LCF in CM_CTL tends to be less than the satellite observations, as reported previously by Zhang et al. (2005), Karlsson et al. (2008), and Freidenreich and Ramaswamy (2011) with the International Satellite Cloud Climatology Project (ISCCP) data (Rossow and Schiffer 1991, 1999). Nevertheless, the simulated seasonality of LCF is overall reasonable under the realistically reproduced seasonality of the Mascarene high in the zonally asymmetric field of sea level pressure (SLP*; hereafter, a zonally asymmetric component is indicated by an asterisk) (Fig. 1), despite slightly overestimated intensity of the high in the model.

Consistent with LCF, the simulated cloud radiative effect shown in Fig. 3 overall captures the observed horizontal distribution of the cooling effect by the clouds. Under annual maximum insolation, the negative cloud radiative effect tends to be strongest in summer, especially off the west coast of Australia (Fig. 3e). The negative cloud radiative effect weakens in winter with its enhanced zonal uniformity (Fig. 3g). Despite the underestimated LCF, the cooling effect over the subtropical SIO tends to be stronger in the model than in the observations throughout the year. Presumably, the simulated low-level clouds are optically thicker than observed, resulting in the overestimated negative cloud radiative effect. Investigating marine subtropical low-level clouds in climate models participating in the Fourth Assessment Report for the Intergovernmental Panel on Climate Change (IPCC), Karlsson et al. (2008) found that those models, including CM2.1, tend to simulate "too few" and "too bright" low-level clouds. The resulting biases that may affect our conclusion are discussed in section 4 .

To extract radiative impacts of those marine low-level clouds on the Mascarene high, we conduct another experiment with 
(a) DJF CRE net CERES

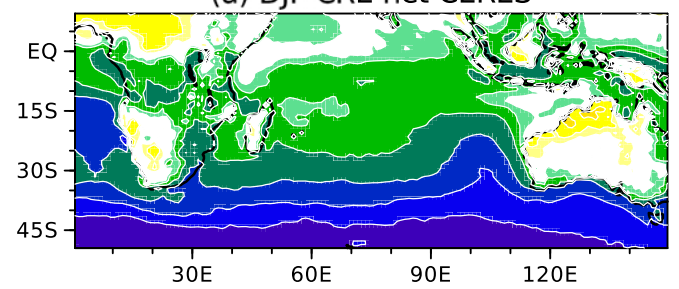

(b) MAM CRE net CERES

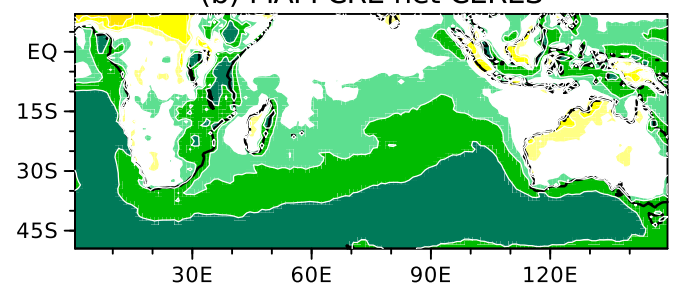

(c) JJA CRE net CERES

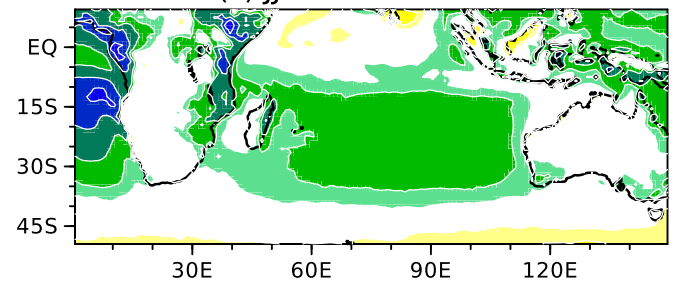

(d) SON CRE net CERES

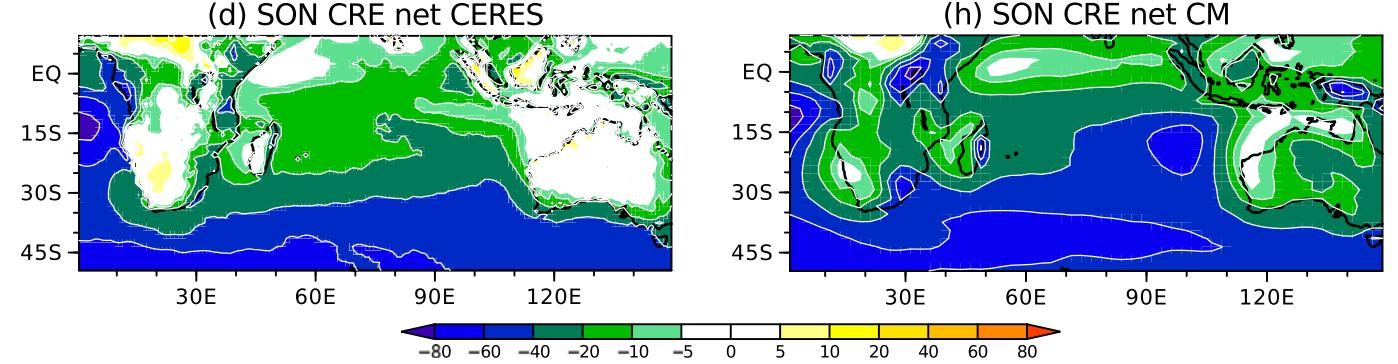

FIG. 3. Climatological distribution of cloud radiative effect $\left(\mathrm{W} \mathrm{m}^{-2}\right)$ in (a) DJF, (b) MAM, (c) JJA, and (d) SON in CERES-EBAF. (e)-(h) As in (a)-(d), respectively, but for the CM_CTL simulation. The uneven coloring convention for all the panels is indicated at the bottom. (e) DJF CRE net CM

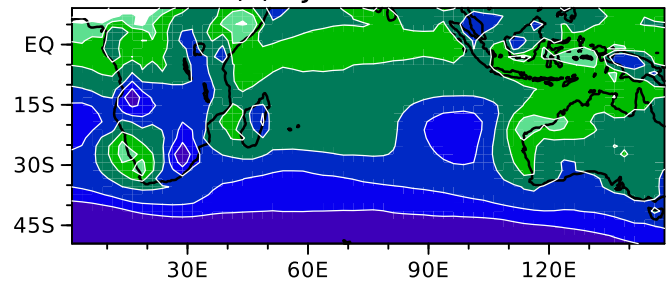

(f) MAM CRE net CM

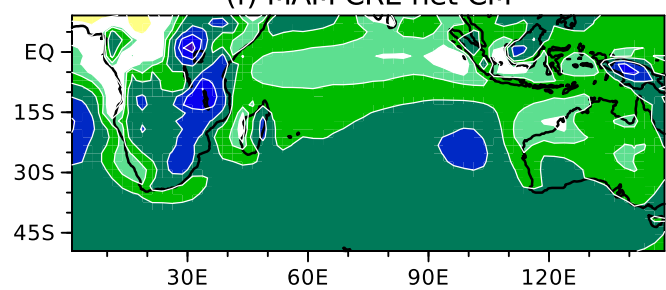

(g) JJA CRE net CM

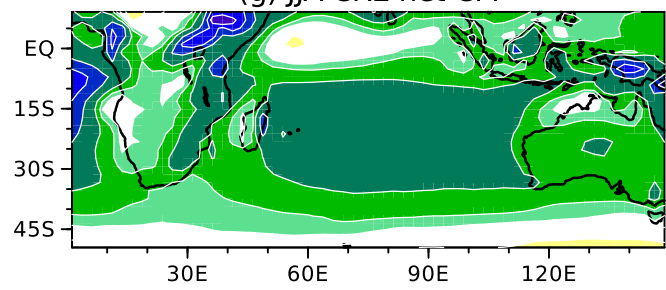

(h) SON CRE net CM 
CM_NoCRE was branched off at 1 January of the 31st year in the CM_CTL simulation and then integrated for 70 years. This study analyzes the last 50 years ending in November. Hereafter, we denote the difference of CM_CTL from CM NoCRE as an "anomaly" that represents a response of the model climate to low-level cloud radiative effect in the subtropical SIO. Despite the fact that TOA imbalance of radiative flux is slightly larger in CM_NoCRE than in CM_CTL (Fig. S1a in the online supplemental material), the excessive heat over the subtropical SIO is stored in the ocean, which has a large heat capacity (Figs. S1d and S2). This ocean heat uptake results in a negligible climatic drift during the last 50 years, as found in surface air temperature averaged over the entire globe (Fig. S1b) and the subtropical SIO (Fig. S1c).

\section{c. Atmospheric general circulation model}

To interpret the aforementioned CGCM experiments, the following set of AGCM experiments have been conducted (Table 1). In one experiment (AM_CTL), we force AM2.1, namely the atmospheric component of $\mathrm{CM} 2.1$, with the climatological-mean SST simulated in CM_CTL. In another experiment with AM2.1 (AM_SSTAstSIO), we add the SST differences (defined as CM_NoCRE-CM_CTL) to the climatological-mean SST only over the subtropical SIO. We also conduct an AM2.1 experiment (AM_NoCRE_SSTclim), in which radiative effect of low-level clouds are eliminated as in CM_NoCRE while SST is fixed to the climatology of CM_CTL. All of the AM2.1 experiments are integrated for 51 years. The 50-yr climatological difference of AM_CTL from AM_SSTAstSIO highlights the impacts of the lowered SST by low-level clouds, whereas that from AM_NoCRE_SSTclim extracts radiative effects of low-level clouds without any changes in SST.

\section{d. Atmospheric dynamical model}

We use a linear baroclinic model (LBM; Watanabe and Kimoto 2000,2001), which is based on the primitive equations linearized about a specified basic state, to investigate an atmospheric response within the framework of dry dynamics to diabatic heating as well as flux convergence of heat and vorticity by submonthly eddies. The horizontal resolution is T42 with 20 vertical $\sigma$ levels. In our LBM, linear damping $r$ for Rayleigh friction and Newtonian cooling is introduced to obtain a steady response:

$$
r=\left\{\begin{array}{l}
(0.5 \text { day })^{-1}(\sigma=0.008,0.025) \\
(20 \text { days })^{-1}(0.035 \leq \sigma \leq 0.830) \\
(10 \text { days })^{-1} \quad(\sigma=0.900) \\
(1 \text { day })^{-1} \quad(\sigma=0.980,0.995) .
\end{array}\right.
$$

The strong damping near the surface mimics surface effects, whereas the strong damping at the uppermost layers is introduced for suppressing unrealistic downward reflection of waves generated below. We also apply $\nabla^{6}$ horizontal hyperdiffusion, whose magnitude is defined in such a way that the $e$-folding time for the largest wavenumber (T42) is $20 \mathrm{~min}$. We have confirmed that our conclusions are rather insensitive to the specific values of those parameters for damping and diffusion (not shown). The model was initialized with a specific basic state and then integrated for 29 days with a prescribed forcing. An average over the last 5 days is regarded as an equilibrium response to the forcing.

\section{Radiative impacts of low-level clouds on the summertime Mascarene high simulated in CM2.1}

\section{a. Seasonal evolution of the SST anomaly}

Figures 4a-d show the SST anomaly in each season. Consistent with the negative cloud radiative effect (i.e., cooling effect) of lowlevel clouds, the SST anomalies are negative in all seasons over the subtropical SIO. The negative SST anomalies are the most prominent in summer (Fig. 4a), with its maximum reaching $\sim-4^{\circ} \mathrm{C}$ in the eastern portion of the basin around $20^{\circ} \mathrm{S}, 95^{\circ} \mathrm{E}$. In winter, the zonal inhomogeneity of the SST anomalies diminishes, and they are $\sim-2^{\circ} \mathrm{C}$ across the basin (Fig. $4 \mathrm{c}$ ).

Consistent with the year-round negative SST anomalies (Figs. 4a-d), the corresponding anomalies in downward shortwave flux are also negative almost over the subtropical SIO in all seasons. The strongest anomalies are found over the eastern portion of the basin in spring and summer under the strong solar insolation and high LCF (Figs. 4e,h). Thus, lowlevel clouds act to cool the underlying ocean by reflecting solar radiation, consistent with the seasonality of the negative SST anomalies (Figs. 4a-d).

The ocean mixed-layer heat budget described below substantiates the contribution of the albedo effect to the development of the negative SST anomalies quantitatively. The anomalous rate of change in mixed-layer temperature (MLT) is due to the net downward surface heat flux (NSHF) anomaly excluding the penetration of the solar radiation into a deeper layer, and the anomalous oceanic effect, which is estimated as the residual (e.g., Morioka et al. 2010):

$$
\left(\frac{\partial \mathrm{MLT}}{\partial t}\right)^{\prime}=\left(\frac{F}{\rho c_{p} H}\right)^{\prime}+(\text { oceanic term }),
$$

where primes denote anomalies defined as $\mathrm{CM}_{-} \mathrm{CTL}-\mathrm{CM}_{-}$ NoCRE. In (2), $F, \rho$, and $c_{p}$ denote NSHF, seawater density $\left(1026 \mathrm{~kg} \mathrm{~m}^{-3}\right)$, and specific heat $\left(3990 \mathrm{~J} \mathrm{~kg}^{-1}{ }^{\circ} \mathrm{C}^{-1}\right)$, respectively, whereas $H$ represents time-varying mixed layer depth (MLD) defined as the depth at which buoyancy difference is $0.0003 \mathrm{~m} \mathrm{~s}^{-2}$ relative to the surface. The first term on the RHS of (2) can be written as

$$
\left(\frac{F}{\rho c_{p} H}\right)^{\prime}=\frac{F^{\prime}}{\rho c_{p} \bar{H}}-\frac{\bar{F} H^{\prime}}{\rho c_{p} \bar{H}^{2}}-\frac{F^{\prime} H^{\prime}}{\rho c_{p} \bar{H}^{2}},
$$

where overbars denote monthly climatologies in CM_NoCRE. The first, second, and third terms on the RHS of (3) represent the effects of anomalous NSHF under the climatological-mean MLD, anomalous MLD under the climatological-mean $F$, and their covariance, respectively.

We apply the budget analysis to the domain off the west coast of Australia $\left(15^{\circ}-25^{\circ} \mathrm{S}, 90^{\circ}-100^{\circ} \mathrm{E}\right.$; indicated by black boxes in Fig. 4), where the negative SST anomaly maximizes in summer. Figures $5 \mathrm{a}$ and $5 \mathrm{~b}$ show the domain-averaged MLT 
(a) DJF SST \& US CTL-NOCRE

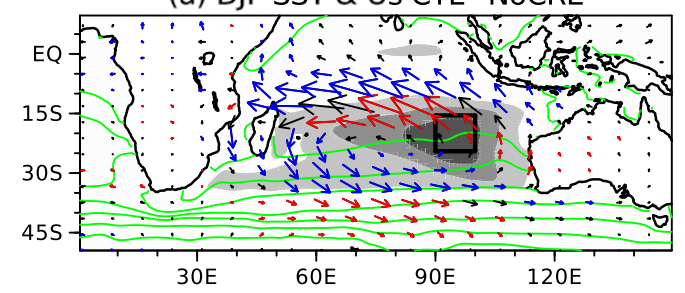

(b) MAM SST \& US CTL-NoCRE

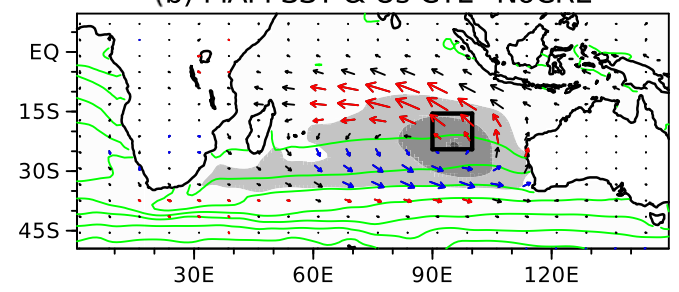

(c) JJA SST \& US CTL-NoCRE

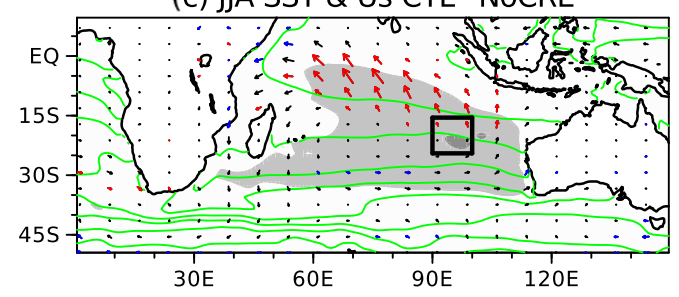

(d) SON SST \& US CTL-NoCRE

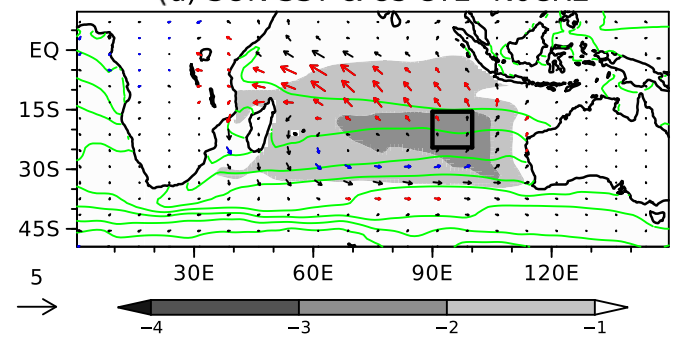

(e) DJF SWdn CTL-NoCRE

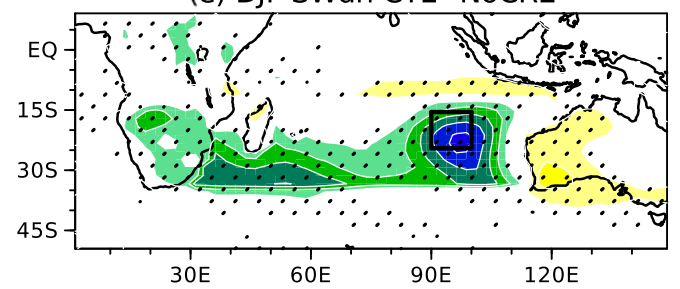

(f) MAM SWdn CTL-NoCRE

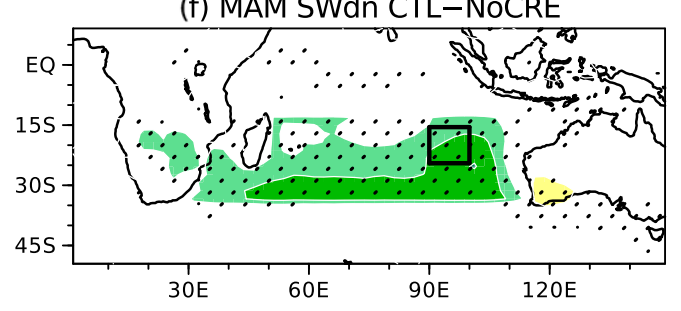

(g) JJA SWdn CTL-NoCRE

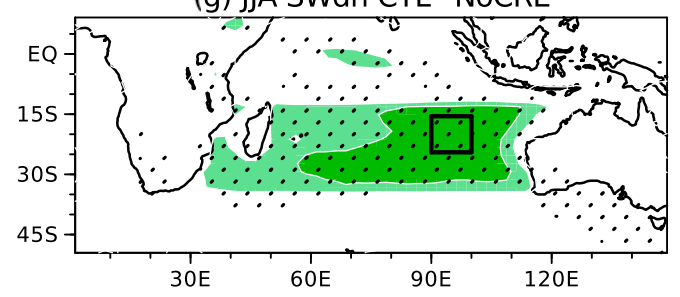

(h) SON SWdn CTL-NoCRE

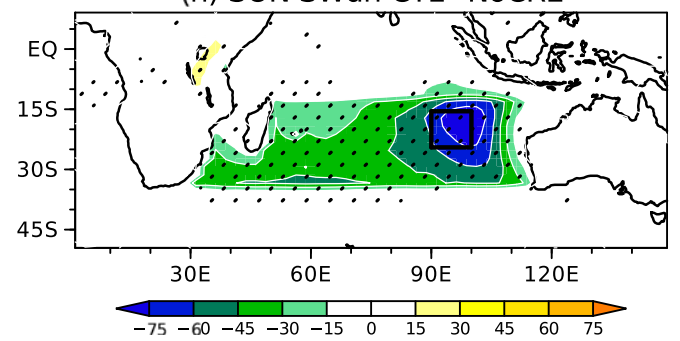

FIG. 4. Difference (defined as CM_CTL - CM_NoCRE) of climatological-mean SST (shaded every $1^{\circ} \mathrm{C}$ ) and surface winds ( $\mathrm{m} \mathrm{s}^{-1}$; arrows with reference on the left; red and blue arrows signify increased and decreased scalar wind speed, respectively, with the $99 \%$ confidence for the difference) in (a) DJF, (b) MAM, (c) JJA, and (d) SON. Superimposed with green contours is climatological-mean SST (every $3^{\circ} \mathrm{C}$ ) in CM_NoCRE. Black box denotes the domain where we apply mixed layer heat budget analysis. (e)-(h) As in (a)-(d), respectively, but for surface downward shortwave heat flux (color shaded every $15 \mathrm{~W} \mathrm{~m}^{-2}$ ). Stippling indicates the $99 \%$ confidence for the difference.

anomaly and its time tendency, respectively. The negative MLT anomaly starts developing in late winter, then maximizes in summer $\left(\sim-4^{\circ} \mathrm{C}\right)$ before decaying in autumn until early winter (Fig. 5a). The contribution from the anomalous NSHF term tends to be concomitant with the amplification of the negative MLT anomaly in spring through summer, while the anomalous oceanic term acts as damping (Fig. 5b). Although the origin of the damping by the oceanic term has not been fully clarified yet, it may be attributable in part to enhanced surface easterlies (Fig. 4a; section 3b), which cause anomalous warm Ekman advection.
As indicated in Fig. 5c with a red line, a contribution from changes in the NSHF term under the climatological-mean MLD [the first term on the RHS of (3)] acts to lower MLT in most of the year. This MLT cooling effect strengthens during spring and then maximizes in early summer, accounting for most of the net MLT tendency due to the (total) NSHF term (Fig. 5b). Decomposition of the anomalous NSHF reveals that reduced solar heating accounts for the cooling effect by NSHF and its time evolution, which is counteracted by the other flux components (Fig. 5c). The time evolution of the cooling by the reduced shortwave radiation is further augmented by the 
(a) MLT

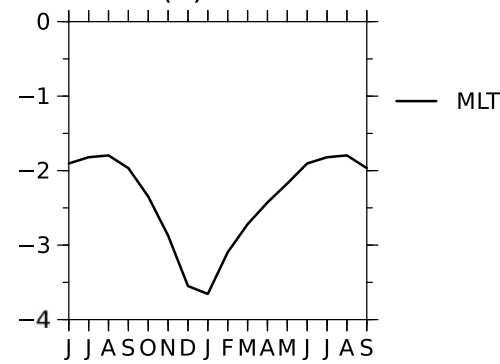

(b) $d M L T / d t$

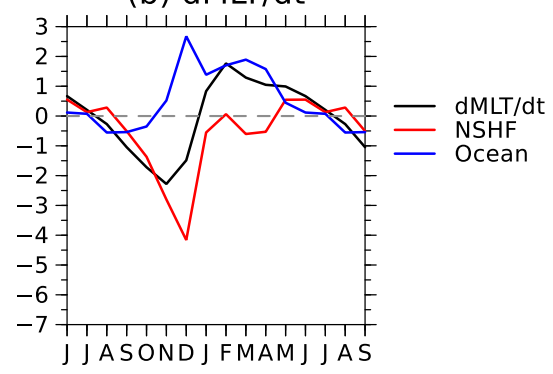

(c) $\mathrm{F}^{\prime} / \rho \mathrm{C}_{\mathrm{p}} \mathrm{H}_{\text {NoCRE }}$

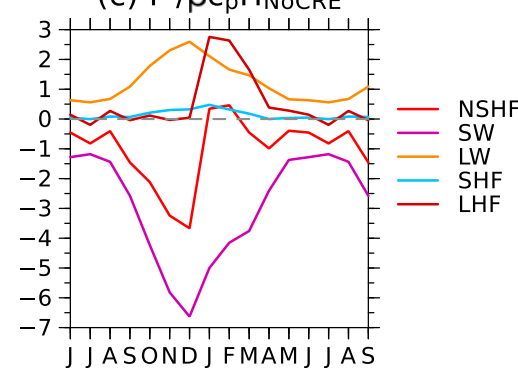

FIG. 5. Difference (defined as CM_CTL - CM_NoCRE) of (a) climatological-mean MLT $\left({ }^{\circ} \mathrm{C}\right)$ and (b) its anomalous rate of change $\left(10^{-7 \circ} \mathrm{C} \mathrm{s}^{-1}\right.$; black line) off the west coast of Australia. Red and blue lines in (b) are NSHF and oceanic terms $\left(10^{-7 \circ} \mathrm{C} \mathrm{s}^{-1}\right)$ in $(3)$. (c) As in (b), but for the NSHF term with climatological-mean $\operatorname{MLD}\left(F^{\prime} / \rho c_{p} \bar{H}\right.$; red line) and its individual contributions from shortwave radiation (SW; purple line), longwave radiation (LW; orange line), sensible heat flux (SHF; light blue line), and latent heat flux (LHF; brown line) anomalies. The panels show 1 year starting from June, and additional 4 months ending in September.

climatologically shallower summertime MLD as in the observations (Fig. S3). The anomalous shortwave cooling is consistent with the negative cloud radiative effect (Figs. 3e-h), which is induced by enhanced LCF (Figs. 2e-h) while being offset partially by midlevel and high-level clouds associated with suppressed deep convection (Figs. 7c and 10a; sections 3c and 3d). Anomalously deeper MLD in the subtropical SIO due to reduced surface heating acts to lower the sensitivity of MLT to summertime climatological heating [the second term on the RHS of (3); Morioka et al. 2010], yielding an additional contribution to the negative MLT anomaly (not shown). Thus, the mixed-layer heat budget analysis supports the importance of the albedo effect of low-level clouds on the evolution of the SST anomaly over the subtropical SIO.

As noted by Xie et al. (2010), anomalous surface latent heat flux is a mixture of SST response and atmospheric forcing. The atmospheric forcing is indeed implied in the mixed-layer heat budget analysis (Fig. 5c), in which anomalous latent heat flux is almost unchanged until December despite the developing SST anomaly. It reflects anomalous anticyclonic circulation (i.e., the enhanced Mascarene high) that strengthens with the enhancing SST anomalies from spring to summer (Figs. 4a and 4d; section $3 \mathrm{~b}$ ). The associated equatorward shift and strengthening of the southeasterly trade winds augment scalar wind speed and yield anomalous cold advection equatorward of $20^{\circ} \mathrm{S}$ (Figs. 4a,d), promoting turbulent heat loss from the subtropical SIO. Over the southwestern portion of the subtropical SIO, by contrast, weakened trade winds and the resultant anomalous warm advection suppress turbulent heat loss. This atmospheric feedback results in the stronger negative SST anomalies in the equatorward portion of the subtropical SIO than its poleward portion (Figs. 4a,d), despite the opposing latitudinal dependence of the shortwave radiation anomalies (Figs. 4e,h).

\section{b. Reinforcement of the summertime Mascarene high by low-level clouds}

Here, we investigate the impacts of low-level clouds on the summertime subtropical high, manifested as a significant positive SLP anomaly centered at $25^{\circ} \mathrm{S}, 75^{\circ} \mathrm{E}$ (Fig. 6a). Compared with the climatological center $\left(30^{\circ} \mathrm{S}, 90^{\circ} \mathrm{E}\right)$ of the Mascarene high as the planetary-wave component (Fig. 1e), the positive
SLP anomaly induced by low-level clouds is displaced slightly westward and equatorward. Thus, low-level clouds act not only to reinforce the high but also to expand it westward and equatorward. The amplitude of the SLP anomaly exceeds $5 \mathrm{hPa}$. In fact, the subtropical high is simulated realistically in CM_CTL as the zonally asymmetric component but almost vanishes in CM_NoCRE (Fig. 6b). The weak surface high around $30^{\circ}-45^{\circ} \mathrm{S}$ simulated in CM_NoCRE is probably attributable to the forcing by active transient eddies in the midlatitude SIO and the land-sea thermal contrast across the west coast of Australia (Miyasaka and Nakamura 2010). The latter is weaker than in CM_CTL owing to the warmer SIO (Fig. 4a). We have also found that the upper-tropospheric meridional vorticity dipole above the surface high, which is dynamically consistent with the midtropospheric subsidence east of the high (Miyasaka and Nakamura 2010), diminishes in CM_NoCRE as well (Fig. S4). Including their impacts extending into the upper troposphere, low-level clouds are thus essential for the formation of the summertime surface Mascarene high. We note that $\sim 75 \%$ of the SLP anomaly is attributable to low-level clouds in the eastern portion of the basin, as revealed by an additional CGCM experiment (CM_NoCREeast), in which they are made artificially transparent only east of $75^{\circ} \mathrm{E}$ (Fig. S5).

\section{c. Direct impacts of low-level clouds: In-atmosphere radiative cooling}

To understand the maintenance mechanisms for the surface high pressure anomaly, we examine diabatic heating anomalies, which can be decomposed into the radiation $\left(Q_{\mathrm{rad}}\right)$, condensation (large-scale condensation plus cumulus convection, $\left.Q_{\text {precip }}\right)$, and vertical diffusion $\left(Q_{\mathrm{vdf}}\right)$ terms. First, we discuss inatmosphere radiative cooling by low-level clouds (marked with the direct arrow from "Low-level clouds" to "Subtropical high" in Fig. 11a). Figure 7a shows vertically integrated anomalous $Q_{\text {rad }}$ in summer. The radiative cooling is particularly strong over the central and eastern portions of the subtropical ocean basin $\left(\sim 30 \mathrm{~W} \mathrm{~m}^{-2} ; \sim 20 \%\right.$ of the climatological value of CM_NoCRE). This is attributable to the artificially imposed positive LCF anomaly maximized at $20^{\circ} \mathrm{S}, 100^{\circ} \mathrm{E}$ (Fig. 7b), since low-level clouds accompany cloud-top longwave radiative cooling (e.g., Lilly 1968). In addition, there are 
(a) DJF SLP CTL-NoCRE

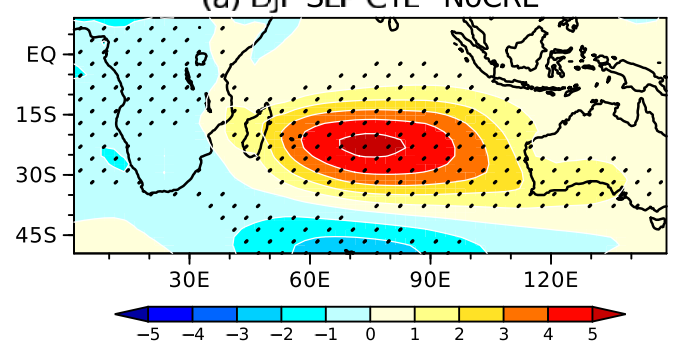

(b) DJF SLP* NOCRE

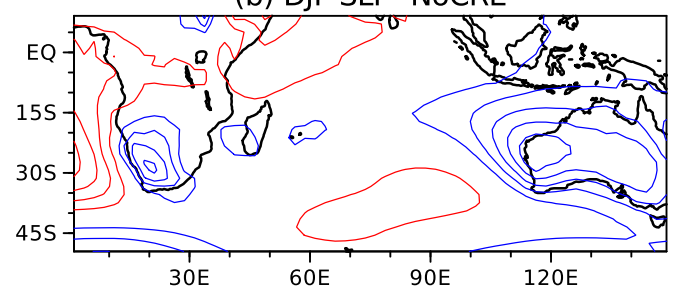

FIG. 6. (a) Summertime (DJF) differences (defined as CM_CTL - CM_NoCRE) of climatological-mean SLP (hPa). Stippling indicates the $99 \%$ confidence for the difference. The coloring convention is indicated at the bottom. (b) Climatological-mean zonally asymmetric SLP (contoured every $1.5 \mathrm{hPa}$; red and blue lines for positive and negative values, respectively; zero contours are omitted) of CM_NoCRE in DJF.

negative high-cloud fraction (HCF) anomalies at the central and eastern portions of the subtropical ocean basin (Fig. 7c). Since high-level clouds act to warm the underlying atmosphere by downward longwave radiation, the reduced HCF also eventually exerts radiative cooling, especially in the equatorward portion of the subtropical basin.

The impacts of the $Q_{\text {rad }}$ anomalies on the surface subtropical high are assessed through experiments with the LBM linearized about the CM_CTL seasonal climatology. The model is forced with the anomalous diabatic heating as well as submonthly eddy heat and vorticity flux convergences, all of which are defined seasonally as the differences between CM_CTL and CM_NoCRE. Figure 8a shows the surface pressure response of the experiments in which the aforementioned forcing is prescribed globally for austral summer. As evident in Fig. 8a, the LBM can reproduce the surface high pressure response over the SIO simulated in the CGCM (Fig. 6a), although the LBM response is slightly shifted westward compared with its CGCM counterpart. The LBM response to the global forcing is mostly due to the anomalous diabatic heating over the subtropical SIO (Fig. 8b).

Figure 9 shows the LBM response to each of the diabatic heating components over the subtropical SIO. The enhanced radiative cooling reinforces the high (Fig. 9b), but it accounts only for one-third of the $Q_{\text {precip }}$ impact (Fig. 9a). Reduced surface turbulent heating from lowered SST may reinforce the high, but the contribution from $Q_{\mathrm{vdf}}$ is almost negligible
(Fig. 9c). Thus, radiative cooling from low-level clouds exerts only modest impacts on the maintenance of the summertime Mascarene high, and the maintenance of the high is mainly due to reduced precipitation and therefore $Q_{\text {precip}}$.

\section{d. Indirect impacts of low-level clouds: Lowered SST}

Motivated by the dominant impacts of $Q_{\text {precip }}$ in the LBM response (Fig. 9a), we investigate anomalous $Q_{\text {precip }}$ and its relationship with the lowered SST in the CGCM experiments. Figure 10a shows the vertically integrated $Q_{\text {precip }}$ anomaly, which is almost equivalent to the precipitation anomaly in the CGCM experiments. Condensation heating is reduced across the subtropical SIO except around $30^{\circ} \mathrm{S}, 55^{\circ} \mathrm{E}$, and the reduction is the most prominent in the equatorward portion of the subtropics (by more than half of the climatological value of CM_NoCRE). The vertical profile of the $Q_{\text {precip }}$ anomaly indicates its deep structure (not shown), and this anomaly can therefore be regarded as reduced activity of deep convection. This is why the reduced $Q_{\text {precip }}$ is consistent with the reduced HCF (Fig. 7c). The cooling anomaly acts to reinforce the surface subtropical high to its southwest (Fig. 9a) as a MatsunoGill type response (Matsuno 1966; Gill 1980), accounting for the major fraction of the impacts of low-level clouds on the summertime Mascarene high.

To discuss the origin of the reduced $Q_{\text {precip }}$, we relate it to the lowered SST by low-level clouds (Fig. 10d). As shown in section $3 \mathrm{a}$, the albedo effect of low-level clouds leads the (a) DJF Qrad CTL-NoCRE

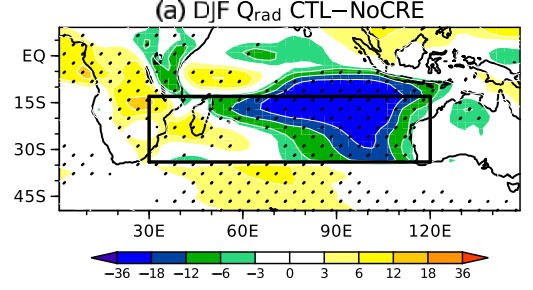

(b) DJF LCF CTL-NoCRE

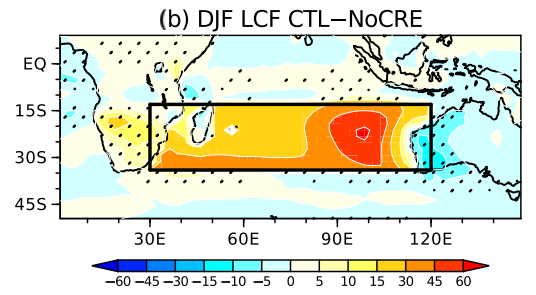

(c) DJF HCF CTL-NoCRE

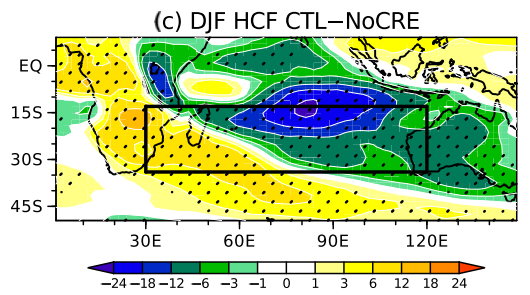

FIG. 7. Summertime (DJF) difference (defined as CM_CTL - CM_NoCRE) of climatological-mean (a) vertically integrated $Q_{\text {rad }}$ $\left(\mathrm{W} \mathrm{m}^{-2}\right.$ ), (b) LCF (\%; cloud-top pressure $\geq 680 \mathrm{hPa}$ ), and (c) HCF ( $\%$; cloud-top pressure $\leq 440 \mathrm{hPa}$ ). Stippling indicates the $99 \%$ confidence for the difference. The uneven coloring convention is indicated at the bottom of each panel. Black rectangular box indicates the domain where low-level clouds are made artificially transparent in the CM_NoCRE simulation. Note that LCF in CM_NoCRE is zero over the subtropical SIO because LCF and HCF are not output directly by the cloud scheme but derived from the cloud fraction used in the radiative transfer calculations. 
(a) LBM Ps
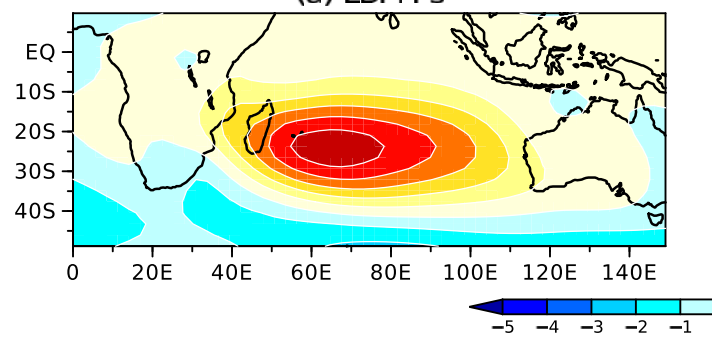

(b) LBM Ps (Q in the subtropical SIO)

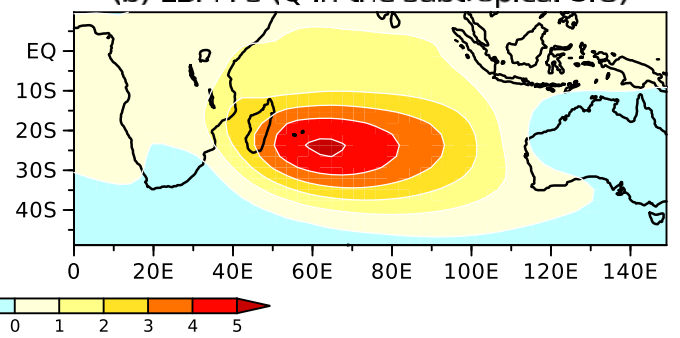

FIG. 8. (a) Surface pressure response (hPa) in the LBM experiment forced with the summertime (DJF) differences (defined as CM_CTL - CM_NoCRE) in diabatic heating and flux convergence of heat and vorticity by submonthly eddies. (b) As in (a), but for the response to anomalies of diabatic heating in the subtropical SIO. The coloring convention is indicated at the bottom.

negative SST anomalies over the subtropical SIO, and their equatorward portion is further enhanced by the strengthened Mascarene high. The cooler SST acts to lower near-surface air temperature and water vapor mixing ratio, and thereby to suppress spontaneous convective activity (e.g., Williams and Renno 1993). To assess this SST effect more quantitatively, we invoke the SST threshold for active convection (e.g., Graham and Barnett 1987). For each of the experiments, the convective threshold is defined as the maximum SST for which the mean precipitation rate falls below $3 \mathrm{~mm}$ day $^{-1}$ (Fig. S6). Our threshold is higher than its counterpart $\left(2 \mathrm{~mm} \mathrm{day}^{-1}\right)$ defined observationally by Johnson and Xie (2010), reflecting the tendency for CM2.1 to overestimate tropical precipitation against given SST compared with the Optimum Interpolation SST V2 (OISST; Reynolds et al. 2002) and the Tropical Rainfall Measuring Mission (TRMM; Huffman et al. 2007) observations (Fig. S6). For both experiments, the SST thresholds are $\sim 27^{\circ} \mathrm{C}\left(26.8^{\circ} \mathrm{C}\right.$ in CM_CTL and $27.2^{\circ} \mathrm{C}$ in $\mathrm{CM}_{-}$ NoCRE), and their isotherms are superimposed in Fig. 10d. Over the SIO, the isotherm for the threshold lies around $20^{\circ}-$ $25^{\circ} \mathrm{S}$ in CM_NoCRE (red line in Fig. 10d), while it lies around $15^{\circ}-20^{\circ} \mathrm{S}$ in CM_CTL (orange line in Fig. 10d). This equatorward displacement of the isotherm means that the ocean cooling by low-level clouds hinders poleward migration and/or expansion of the ITCZ, which is centered at $5^{\circ}-10^{\circ} \mathrm{S}$ in both CM_CTL and observations (Fig. S7). Thus, the negative SST anomaly suppresses convective precipitation mainly in the equatorward portion of the subtropical SIO, resulting in the reduced condensation heating and high-top clouds.

The impacts of the lowered SST on deep convective activity are further supported by comparison of $Q_{\text {precip }}$ in AM_CTL and AM_SSTAstSIO (Fig. 10b). Though somewhat overestimated, reduced $Q_{\text {precip }}$ in the equatorward portion of the subtropical SIO is well captured in the AGCM experiments. As shown in Fig. 10c, by contrast, comparison of AM_CTL and AM_NoCRE_SSTclim exhibits no significant reduction of precipitation in the subtropical SIO (and even a slight increase near the ITCZ). We therefore conclude that low-level clouds suppress precipitation by lowering SST, especially in the equatorward portion of the subtropical SIO.

\section{Concluding remarks}

Figure 11 summarizes the coupling of the surface subtropical Mascarene high with low-level clouds in the SIO, with a particular focus on their feedback demonstrated by the present study. Previous studies showed that the summertime Mascarene high developing off the heated Australian continent (green arrow in Fig. 11a; Miyasaka and Nakamura 2010) promotes the frequent occurrence of low-level clouds directly via subsidence and indirectly via lowered SST (arrows from "Subtropical high" to "Low-level clouds" in Fig. 11a; Klein and Hartmann 1993; Seager et al. 2003; Miyamoto et al. 2018; section 3a of this study). While the positive feedback from low-level clouds on the climatological subtropical high has already been suggested (e.g., Rodwell and Hoskins 2001; Seager et al. 2003; Miyasaka and Nakamura 2005, 2010), we have first confirmed it by artificially eliminating radiative impacts of low-level clouds in a CGCM and then elucidating its mechanisms through AGCM and LBM experiments.

We have demonstrated that low-level clouds are essential for the maintenance of the summertime Mascarene high. Our
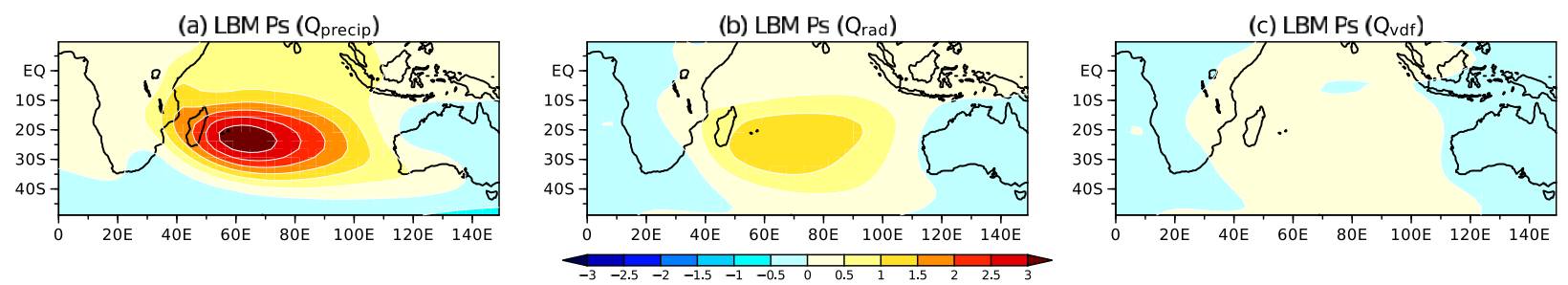

FIG. 9. As in Fig. 8b, but for individual contributions from (a) $Q_{\text {precip }}$, (b) $Q_{\text {rad }}$, and (c) $Q_{\text {vdf. Note that the coloring convention is different }}$ from Fig. 8. 
(a) DJF Qprecip CTL-NoCRE

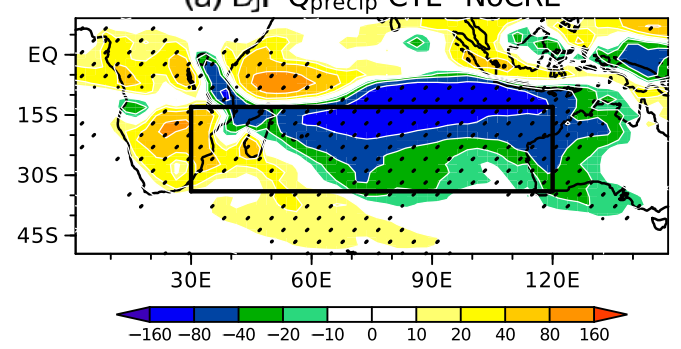

(c) DJF Qprecip AM_CTL-AM_NoCRE_SSTclim

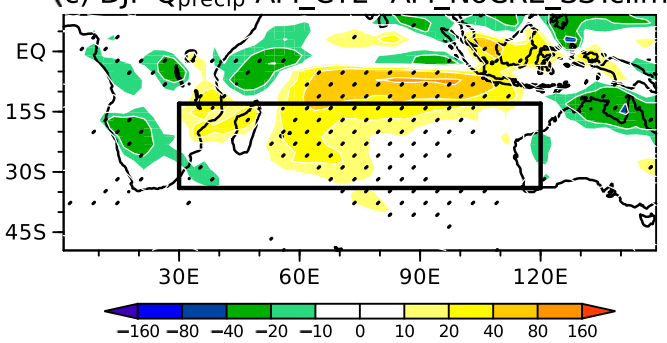

(b) DJF Qprecip AM CTL-AM SSTAstSIO

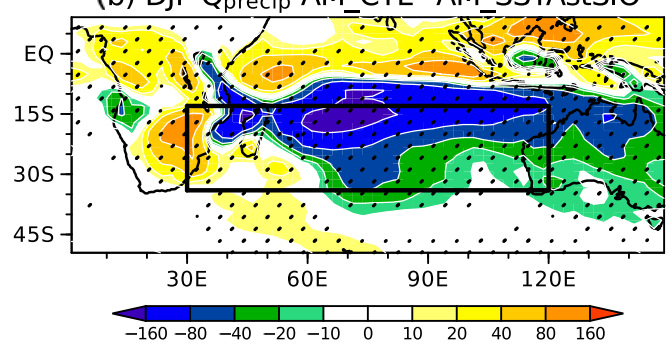

(d) DJF SST CTL-NoCRE

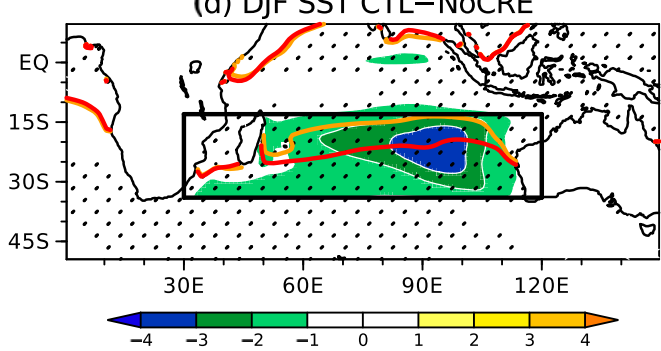

FIG. 10. (a) Summertime (DJF) difference (defined as CM_CTL - CM_NoCRE) of climatological-mean vertically integrated $Q_{\text {precip }}\left(\mathrm{W} \mathrm{m}^{-2}\right)$. (b),(c) As in (a), but for the difference of the AGCM experiments defined as (b) AM_CTL - AM_SSTAstSIO and (c) AM_CTL - AM_NoCRE_SSTclim. (d) As in (a), but for SST with the isotherms of the SST thresholds for active convection in CM_CTL $\left(26.8^{\circ} \mathrm{C}\right.$; orange lines) and CM_NoCRE $\left(27.2^{\circ} \mathrm{C}\right.$; red lines). See text for the details of the convective threshold. Stippling indicates the $99 \%$ confidence for the difference. The coloring convention is indicated at the bottom of each panel. The black rectangular box indicates the domain where low-level clouds are made artificially transparent in CM_NoCRE and AM_NoCRE_SSTclim.

sensitivity experiments with the CGCM have confirmed that low-level clouds reinforce the summertime Mascarene high, but it would almost vanish without them (section $3 b$ ). Under the strong insolation during the warm season, the albedo effect of low-level clouds strongly lowers SST, especially in the eastern portion of the basin (red arrow from "Low-level clouds" to "Subtropical SST" in Fig. 11a; section 3a). The lowered SST hinders the poleward displacement (or expansion) of the ITCZ, reducing precipitation by deep clouds in the equatorward portion of the subtropical SIO. The resultant diabatic cooling induces a surface anticyclonic anomaly to its southwest, reinforcing the subtropical high (red arrow from "Subtropical SST" to "Subtropical high" in Fig. 11a; section 3d). The associated southeasterly trade winds further cool the equatorward portion of the subtropical SIO as positive feedback (red arrow from "Subtropical high" to "Subtropical SST" in Fig. 11a; section 3a). Our dynamical model experiments have elucidated that the reinforcement through the reduced condensation heating is predominant in the feedback from low-level clouds. The high is also reinforced modestly by the augmented in-atmosphere radiative cooling, which is attributable to the reduced longwave radiative heating by highlevel clouds associated with the reduced deep convection as well as to the cloud-top longwave cooling by low-level clouds (red direct arrow from "Low-level clouds" to "Subtropical high" in Fig. 11a; section 3c).

As a typical bias of climate models (Karlsson et al. 2008; Nam et al. 2012), cloud radiative effect in CM_CTL tends to be stronger than its counterpart estimated from satellite observations (Fig. 3; Karlsson et al. 2008), despite the lower LCF (Fig. 2; Karlsson et al. 2008). Although weaker than in summer, the reduction of deep convective precipitation still occurs in the other seasons (not shown) when the negative SST anomalies are weaker than in summer (Figs. 4b-d). Thus, we believe that the summertime weakening of precipitation by deep clouds is a robust result. Regarding the relative importance between the direct longwave cooling from low-level clouds and the reduced precipitation, investigation of the Mascarene high as the planetary wave based on reanalysis datasets further supports the predominance of the reduced precipitation in its maintenance (see appendix). The modest impact of the longwave cooling is also consistent with Kawai and Koshiro (2020), who reported that the summertime subtropical highs in the Northern Hemisphere are not weakened strongly even in the absence of stratocumulus clouds in their AGCM.

The geographical relationship between the summertime subtropical Mascarene high and low-level clouds is similar to that in the other ocean basins (e.g., Klein and Hartmann 1993; Miyasaka and Nakamura 2005, 2010; Miyamoto et al. 2018). We have shown that the artificial removal of cloud radiative effect in a CGCM is a useful method for assessing the impacts of low-level clouds on the subtropical high and it is particularly so if combined with atmospheric dynamical model experiments. With care of model climatic drift and biases, we can apply this methodology to the other subtropical oceans in order to identify common features as well as interbasin 
(a)

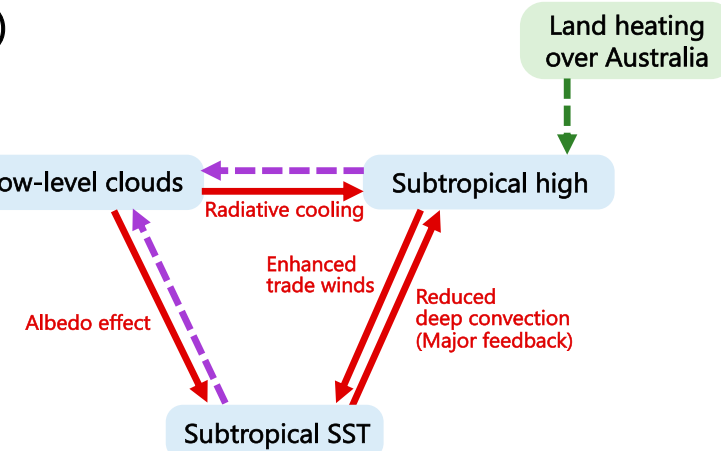

(b)

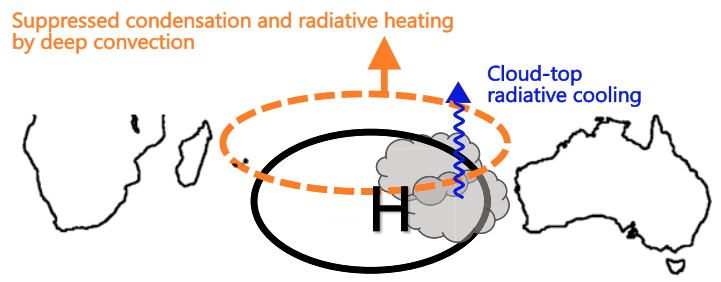

FIG. 11. (a) Schematic diagram showing a positive feedback system associated with the subtropical Mascarene high and lowlevel clouds over the SIO in austral summer. Solid line arrows indicate influences demonstrated by the present study, while dashed line arrows indicate those demonstrated by previous studies. Light blue boxes signify the components of the feedback system associated with low-level clouds, while a light green box signifies a component that can modulate the feedback. (b) Geographical location of each factor in (a), with " $H$ " signifying the subtropical high and low-level clouds indicated by gray shading.

differences. Detailed understanding in air-sea interactions associated over the eastern subtropical oceans may also be helpful for reducing a warm bias of coastal SST in climate models (e.g., Zuidema et al. 2016).

Whether the active roles of low-level clouds elucidated in this study is operative in interannual variations such as the Ningaloo Niño/Niña (e.g., Feng et al. 2013; Kataoka et al. 2014) and the subtropical dipole mode (e.g., Behera and Yamagata 2001) is also interesting. Indeed, cloud changes are observed in the Ningaloo Niño/Niña with notable nonlinearity (Tozuka and Oettli 2018). Furthermore, our study suggests that difficulties in projecting subtropical low-level clouds (Bony and Dufresne 2005; Qu et al. 2014, 2015; Myers and Norris 2016; Zelinka et al. 2020) may introduce uncertainties in future warming of subtropical oceans and thereby in the future projection of subtropical highs ( $\mathrm{Li}$ et al. 2012, 2013; Nakamura 2012; Shaw and Voigt 2015; Fahad et al. 2020). Thorough analyses, including a series of idealized sensitivity experiments (Erfani and Burls 2019), are needed to resolve this issue.

Last, we have not discussed the wintertime feedback from low-level clouds in the present study. We have found that lowlevel clouds also reinforce the wintertime Mascarene high, though less strongly than in summer based on our CGCM experiments (Fig. 4c). Our subsequent paper will discuss not only this seasonal difference and its mechanism but also wintertime

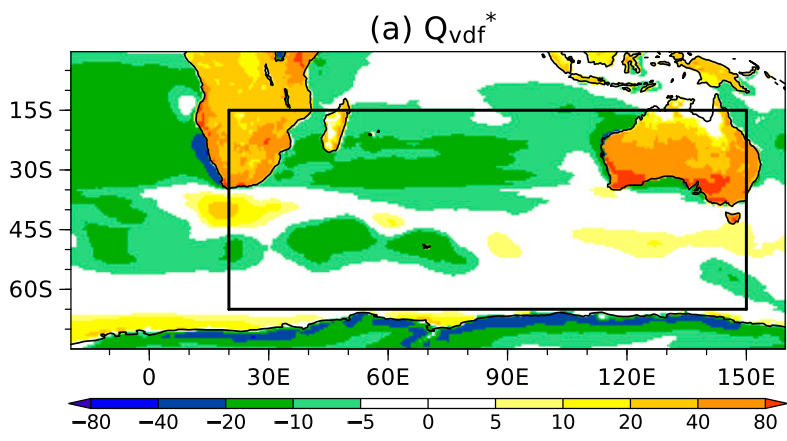

(b) $\mathrm{Qrad}^{*}$

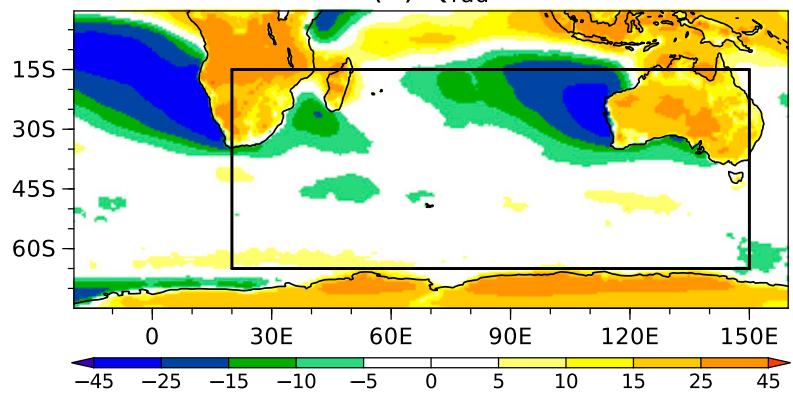

(c) Qprecip ${ }^{*}$

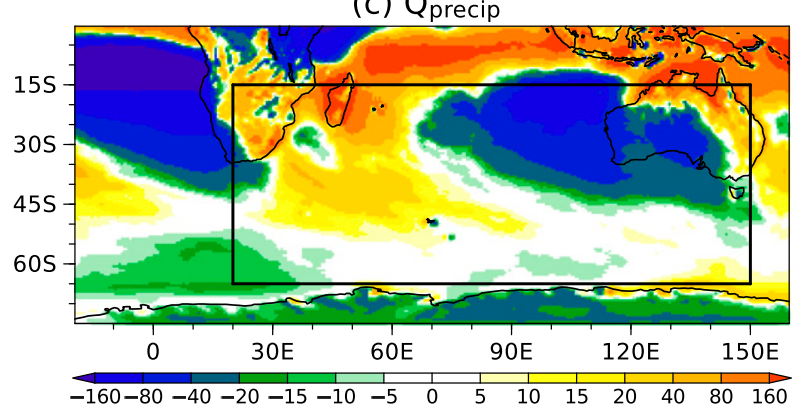

FIG. A1. Climatological-mean summertime (January) distributions of zonally asymmetric vertically integrated (a) $Q_{\mathrm{vdf}}$, (b) $Q_{\mathrm{rad}}$, and (c) $Q_{\text {precip }}$ based on JRA-55. Unit is $\mathrm{W} \mathrm{m}^{-2}$. The uneven coloring convention is indicated at the bottom of each panel. The black box indicates the domain where we prescribe each of the forcing locally in the LBM experiments.

external modulation of the coupled system between the Mascarene high and low-level clouds in more detail, giving a comprehensive view of the coupled system and its distinct seasonality in the SIO.

Acknowledgments. This work is based on AM's doctoral dissertation at the University of Tokyo. Valuable comments by Drs. M. Koike, Y. N. Takayabu, T. Tozuka, K. Suzuki, B. Taguchi, M. Mori, and H. Kawai are acknowledged. We also thank Prof. J. Norris, Prof. S.-P. Xie, and two anonymous reviewers for their constructive comments that have significantly improved this paper. This study is supported in part by the Japanese Ministry of Education, Culture, Sports, Science and Technology (MEXT) through the Arctic Challenge for Sustainability (ArCS-II), by the Japan Science and Technology Agency 
(a) Qvdf ${ }^{*}$

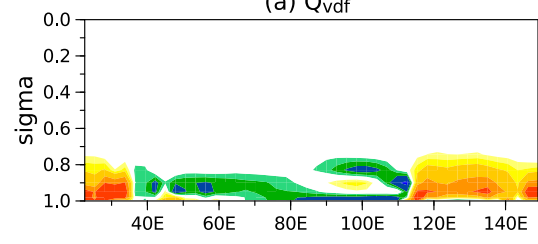

(b) $\mathrm{Qrad}^{*}$

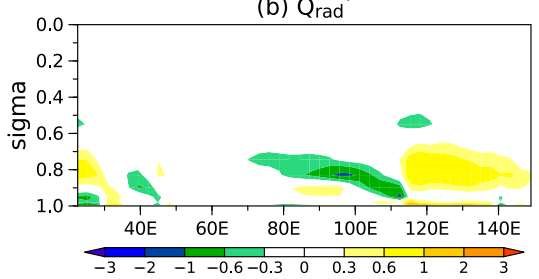

(c) $Q_{\text {precip }}{ }^{*}$

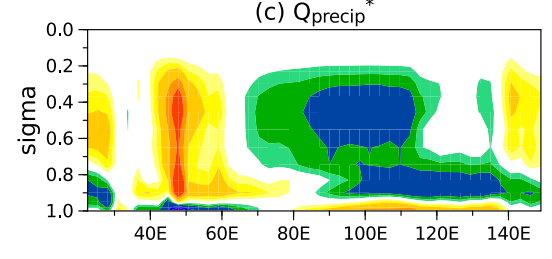

FIG. A2. Climatological-mean summertime (January) longitude-vertical sections of zonally asymmetric (a) $Q_{\text {vdf }}$, (b) $Q_{\text {rad }}$, and (c) $Q_{\text {precip }}\left(\mathrm{K} \mathrm{day}^{-1}\right)$ at $25^{\circ} \mathrm{S}$ based on JRA-55. Unit is $\mathrm{K}_{\text {day }}{ }^{-1}$. The model-level JRA-55 data have been interpolated vertically onto the LBM sigma coordinate. The uneven coloring convention is indicated at the bottom.

through Belmont Forum CRA "InterDec", by the Japanese Ministry of Environment through Environment Research and Technology Development Fund JMEERF20192004, and by the Japan Society for the Promotion of Science (JSPS) through Grants-in-Aid for Scientific Research JP18H01278, JP19H05702, JP19H05703 (on Innovative Areas 6102), and 20H01970.

Data availability statement. All the observational data used in this study are available from the corresponding websites (the JRA-55 atmospheric reanalysis: https://jra.kishou.go.jp/JRA55/index_en.html; the CALIPSO-GOCCP and CERES data: https://climserv.ipsl.polytechnique.fr/cfmip-obs/; the OISST data: https://psl.noaa.gov/).

\section{APPENDIX}

\section{Observed Summertime Mascarene High as the Planetary-Wave Component}

Using an atmospheric dynamical model forced with zonally asymmetric diabatic heating, Miyasaka and Nakamura (2010) investigated the planetary-wave component of the Mascarene high. Although they did not decompose the diabatic cooling into individual components, they argued that cloud-top radiative cooling from low-level clouds is the main direct forcing for the maintenance of the summertime Mascarene high. Here, we prescribe the LBM with January zonally asymmetric components of diabatic heating in JRA-55 as in Miyasaka and Nakamura (2010), to show that the reduced deep-convective condensational heating (or precipitation) is indeed the predominant mechanism for the maintenance of the summertime Mascarene high. Figure A1 shows maps of the imposed diabatic heating after integrated vertically, and the corresponding longitudinal sections are shown in Fig. A2. Model settings are the same as in section 3, except that the basic-state set here is the observed January zonal-mean state.

Figure A3b shows the surface pressure response in the LBM experiment in which all kinds of forcing are prescribed northward of $65^{\circ} \mathrm{S}$, including in the Northern Hemisphere. No forcing is imposed around Antarctica to avoid unrealistically large response. Compared with its observational counterpart (Fig. A3a), the LBM can reproduce the maritime subtropical (a) JAN JRA55

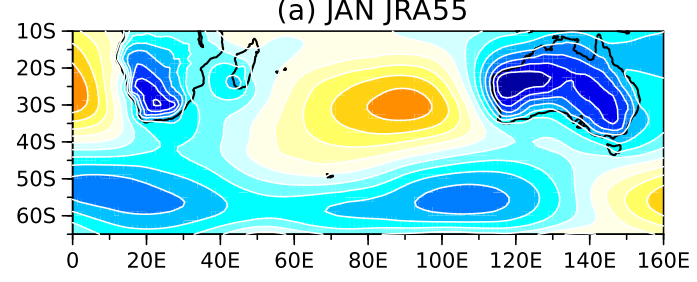

(c) JAN LBM (local Q*)

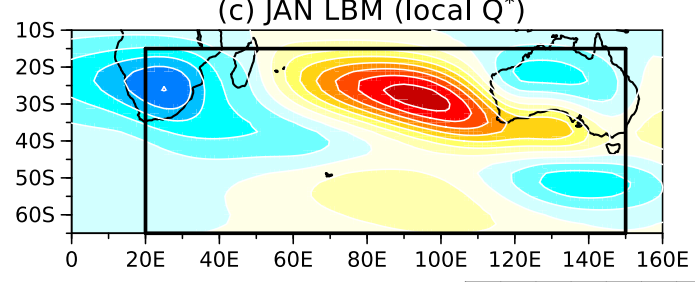

(b) JAN LBM

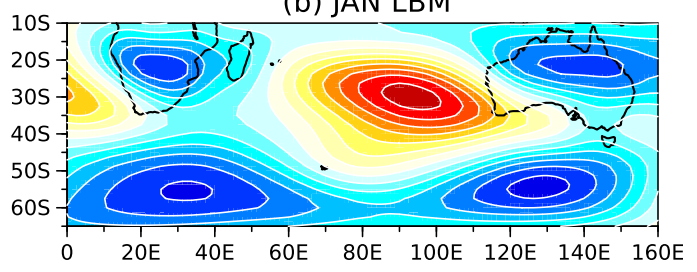

(d) JAN LBM (local sub-monthly eddies)

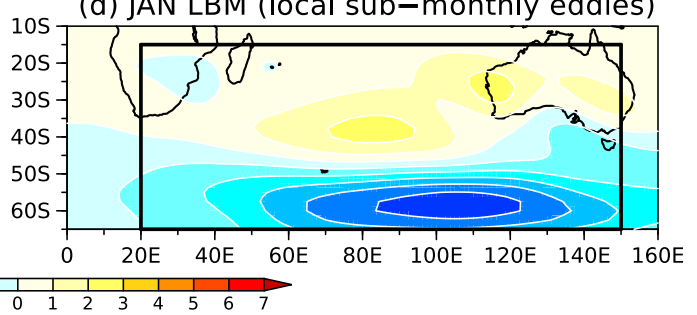

FIG. A3. (a) Zonally asymmetric field of climatological-mean summertime (January) SLP (hPa). (b) Surface pressure response $(\mathrm{hPa})$ in the LBM experiment in which forcing is imposed northward of $65^{\circ} \mathrm{S}$. (c), (d) As in (b), but (c) diabatic heating and (d) flux convergence of heat and vorticity by submonthly eddies are prescribed only locally within a rectangular domain $\left(15^{\circ}-65^{\circ} \mathrm{S}, 20^{\circ}-150^{\circ} \mathrm{E}\right.$; indicated by black box $)$. The coloring convention is indicated at the bottom. 

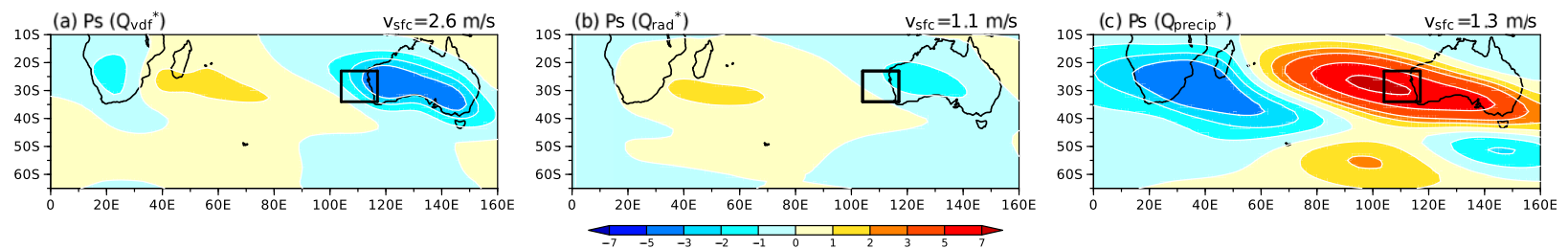

FIG. A4. As in Fig. A3c, but for individual contributions from (a) $Q_{\mathrm{vdf}}^{*}$, (b) $Q_{\text {rad }}^{*}$, and (c) $Q_{\text {precip. The uneven coloring convention is }}^{*}$ indicated at the bottom. In each panel, surface meridional wind $\left(\mathrm{m} \mathrm{s}^{-1}\right)$ averaged within a rectangular domain $\left(23^{\circ}-34^{\circ} \mathrm{S}, 104^{\circ}-117^{\circ} \mathrm{E}\right.$; indicated by black box) is shown at the title.

high, which is overestimated in the current parameter setting though. We have confirmed that elevated linear damping can reduce its total amplitude without affecting relative importance among the different diabatic heating components (not shown). The LBM also captures but underestimates the associated continental low over Australia. As demonstrated in another experiment in which diabatic heating is imposed only over the SIO and the adjacent Australian continent, it is the local diabatic heating that primarily accounts for the maintenance of the summertime Mascarene high (Fig. A3c). It should be noted that submonthly eddies reinforce the enhanced westerlies around $50^{\circ} \mathrm{S}$ with the modest high pressure response centered at $35^{\circ} \mathrm{S}, 85^{\circ} \mathrm{E}$, acting to expand the maritime high poleward (Fig. A3d; Miyasaka and Nakamura 2010).

Figure A4 decomposes the response into the contributions from individual local heating components. Inconsistent with Miyasaka and Nakamura (2010), maritime cooling of $Q_{\mathrm{vdf}}^{*}$ and $Q_{\text {rad }}^{*}$ (Figs. A1a,b, and A2a,b) exerts only a minor impact on the maintenance of the maritime high (Figs. A4a,b). By contrast, reduction of deep condensation heating over the eastern subtropical SIO (Figs. A1c and A2c) accounts for most of the anticyclonic response in the LBM (Fig. A4c). Although Miyasaka and Nakamura (2010) regarded the lowertropospheric cooling as the $Q_{\mathrm{vdf}}^{*}$ and $Q_{\mathrm{rad}}^{*}$ combined, a lowertropospheric $Q_{\text {precip }}^{*}$ actually yields a major contribution to the total cooling (Fig. A2c). In fact, the lower-tropospheric $Q_{\text {precip }}^{*}$ $(\sigma \geq 0.65)$ explains almost half of the anticyclonic response to the full-depth $Q_{\text {precip }}^{*}$ (Fig. S8). We have confirmed that our conclusions do not change if we use other reanalysis datasets such as the Japanese 25-year Reanalysis (JRA-25; Onogi et al. 2007) and the National Centers for Environmental Prediction (NCEP)-Department of Energy (DOE) Reanalysis 2 (NCEP-R2; Kanamitsu et al. 2002), both of which provide individual diabatic heating components (not shown). Thus, the reduced deep-convective condensational heating (or precipitation) is the predominant mechanism for the maintenance of the planetary-wave component of the summertime surface Mascarene high.

It should be noted, however, that the shallow heating contrasts across the west coast of Australia (Figs. A1a,b and A2a,b) can still be important for the development of the Mascarene high by triggering surface equatorward winds (Figs. A4a,b). As indicated by Miyasaka and Nakamura
(2005, 2010), the shallow land-sea heating-cooling couplet forces surface warm and cold anomalies, and thereby the continental low and maritime high (Figs. A4a,b) as potential vorticity anomalies (Hoskins et al. 1985). The associated alongshore equatorward winds act to cool the underlying ocean by enhancing surface evaporation, coastal upwelling, entrainment at the ocean mixed layer bottom, and possibly the weakening of the warm Leeuwin Current (e.g., Rodwell and Hoskins 2001; Seager et al. 2003; Kataoka et al. 2014). These winds also accompany surface divergence and midtropospheric subsidence under the Sverdrup vorticity balance (Rodwell and Hoskins 2001; Miyasaka and Nakamura 2005, 2010). The lowered SST and midtropospheric subsidence favor (hamper) the formation of low-level (deep-convective) clouds. We therefore argue that the local amplification mechanism suggested by Miyasaka and Nakamura (2010) should be modified by incorporating the suppression of deep-convective precipitation as an important mechanism, in which low-level clouds play an integral role.

\section{REFERENCES}

Albern, N., A. Voigt, S. A. Buehler, and V. Grützun, 2018: Robust and nonrobust impacts of atmospheric cloud-radiative interactions on the tropical circulation and its response to surface warming. Geophys. Res. Lett., 45, 8577-8585, https://doi.org/ 10.1029/2018GL079599.

Behera, S. K., and T. Yamagata, 2001: Subtropical SST dipole events in the Southern Indian Ocean. Geophys. Res. Lett., 28, 327-330, https://doi.org/10.1029/2000GL011451.

Bony, S., and J.-L. Dufresne, 2005: Marine boundary layer clouds at the heart of tropical cloud feedback uncertainties in climate models. Geophys. Res. Lett., 32, L20806, https://doi.org/ 10.1029/2005GL023851.

Chepfer, H., S. Bony, D. M. Winker, G. Cesana, J. Dufresne, P. Minnis, C. Stubenrauch, and S. Zeng, 2010: The GCMOriented CALIPSO Cloud Product (CALIPSO-GOCCP). J. Geophys. Res., 115, D00H16, https://doi.org/10.1029/ 2009JD012251.

Crueger, T., and B. Stevens, 2015: The effect of atmospheric radiative heating by clouds on the Madden-Julian Oscillation. J. Adv. Model. Earth Syst., 7, 854-864, https://doi.org/10.1002/ 2015MS000434.

Delworth, T. L., and Coauthors, 2006: GFDL's CM2 global coupled climate models. Part I: Formulation and simulation 
characteristics. J. Climate, 19, 643-674, https://doi.org/10.1175/ JCLI3629.1.

Dima, I. M., and J. M. Wallace, 2003: On the seasonality of the Hadley cell. J. Atmos. Sci., 60, 1522-1527, https://doi.org/ 10.1175/1520-0469(2003)060<1522:OTSOTH $>2.0$. CO; 2 .

Erfani, E., and N. J. Burls, 2019: The strength of low-cloud feedbacks and tropical climate: A CESM sensitivity study. J. Climate, 32, 2497-2516, https://doi.org/10.1175/JCLI-D-180551.1.

Fahad, A., N. J. Burls, and Z. Strasberg, 2020: How will Southern Hemisphere subtropical anticyclones respond to global warming? Mechanisms and seasonality in CMIP5 and CMIP6 model projections. Climate Dyn., 55, 703-718, https://doi.org/ 10.1007/s00382-020-05290-7.

Feng, M., M. J. McPhaden, S.-P. Xie, and J. Hafner, 2013: La Niña forces unprecedented Leeuwin Current warming in 2011. Sci. Rep., 3, 1277, https://doi.org/10.1038/srep01277.

Fermepin, S., and S. Bony, 2014: Influence of low-cloud radiative effects on tropical circulation and precipitation. J. Adv. Model. Earth Syst., 6, 513-526, https://doi.org/10.1002/2013MS000288.

Freidenreich, S., and V. Ramaswamy, 2011: Analysis of the biases in the downward shortwave surface flux in the GFDL CM2.1 general circulation model. J. Geophys. Res., 116, D08208, https://doi.org/10.1029/2010JD014930.

Gill, A. E., 1980: Some simple solutions for heat-induced tropical circulation. Quart. J. Roy. Meteor. Soc., 106, 447-462, https:// doi.org/10.1002/qj.49710644905.

Gordon, C. T., A. Rosati, and R. Gudgel, 2000: Tropical sensitivity of a coupled model to specified ISCCP low clouds. J. Climate, 13, 2239-2260, https://doi.org/10.1175/1520-0442(2000)013<2239: TSOACM $>2.0 . \mathrm{CO} ; 2$.

Graham, N. E., and T. P. Barnett, 1987: Sea surface temperature, surface wind divergence, and convection over tropical oceans. Science, 238, 657-659, https://doi.org/10.1126/science.238.4827.657.

Harada, Y., and Coauthors, 2016: The JRA-55 reanalysis: Representation of atmospheric circulation and climate variability. J. Meteor. Soc. Japan, 94, 269-302, https://doi.org/ 10.2151/jmsj.2016-015.

Harrop, B. E., and D. L. Hartmann, 2016: The role of cloud radiative heating in determining the location of the ITCZ in aquaplanet simulations. J. Climate, 29, 2741-2763, https:// doi.org/10.1175/JCLI-D-15-0521.1.

Hartmann, D. L., and D. A. Short, 1980: On the use of Earth radiation budget statistics for studies of clouds and climate. J. Atmos. Sci., 37, 1233-1250, https://doi.org/10.1175/15200469(1980)037<1233:OTUOER>2.0.CO;2.

Held, I. M., and I. Y. Hou, 1980: Nonlinear axially symmetric circulations in a nearly inviscid atmosphere. J. Atmos. Sci., 37, 515-533, https://doi.org/10.1175/1520-0469(1980)037<0515: NASCIA $>2.0 . \mathrm{CO} ; 2$.

Hoskins, B. J., M. E. McIntyre, and A. W. Robertson, 1985: On the use and significance of isentropic potential vorticity maps. Quart. J. Roy. Meteor. Soc., 111, 877-946, https://doi.org/ 10.1002/qj.49711147002.

Huffman, G. J., and Coauthors, 2007: The TRMM Multisatellite Precipitation Analysis (TMPA): Quasi-global, multiyear, combined-sensor precipitation estimates at fine scales. J. Hydrometeor., 8, 38-55, https://doi.org/10.1175/JHM560.1.

Johnson, N. C., and S.-P. Xie, 2010: Changes in the sea surface temperature threshold for tropical convection. Nat. Geosci., 3, 842-845, https://doi.org/10.1038/ngeo1008.

Kanamitsu, M., W. Ebisuzaki, J. Woollen, S.-K. Yang, J. J. Hnilo, M. Fiorino, and G. L. Potter, 2002: NCEP-DOE AMIP-II
Reanalysis (R-2). Bull. Amer. Meteor. Soc., 83, 1631-1644, https://doi.org/10.1175/BAMS-83-11-1631.

Karlsson, J., G. Svensson, and H. Rodhe, 2008: Cloud radiative forcing of subtropical low level clouds in global models. Climate Dyn., 30, 779-788, https://doi.org/10.1007/s00382-0070322-1.

Kataoka, T., T. Tozuka, S. Behera, and T. Yamagata, 2014: On the Ningaloo Niño/Niña. Climate Dyn., 43, 1463-1482, https:// doi.org/10.1007/s00382-013-1961-z.

Kawai, H., and T. Koshiro, 2020: Does radiative cooling of stratocumulus strengthen summertime subtropical highs? Research Activities in Earth System Modelling, Working Group on Numerical Experimentation. Rep. 50, WCRP Rep. 12/2020, WMO, 11-12, http://bluebook.meteoinfo.ru/uploads/ 2020/docs/07_Kawai_Hideaki_SubtropicalHighs.pdf.

Kawamura, R., T. Matsuura, and S. Iizuka, 2001: Role of equatorially asymmetric sea surface temperature anomalies in the Indian Ocean in the Asian summer monsoon and El NiñoSouthern Oscillation coupling. J. Geophys. Res., 106, 46814693, https://doi.org/10.1029/2000JD900610.

Klein, S. A., and D. L. Hartmann, 1993: The seasonal cycle of low stratiform clouds. J. Climate, 6, 1587-1606, https://doi.org/ 10.1175/1520-0442(1993)006<1587:TSCOLS > 2.0.CO;2.

Kobayashi, S., and Coauthors, 2015: The JRA-55 reanalysis: General specifications and basic characteristics. J. Meteor. Soc. Japan, 93, 5-48, https://doi.org/10.2151/jmsj.2015-001.

Koseki, S., T. Nakamura, H. Mitsudera, and Y. Wang, 2012: Modeling low-level clouds over the Okhotsk Sea in summer: Cloud formation and its effects on the Okhotsk high. J. Geophys. Res., 117, D05208, https://doi.org/10.1029/ 2011JD016462.

Koshiro, T., and M. Shiotani, 2014: Relationship between low stratiform cloud amount and estimated inversion strength in the lower troposphere over the global ocean in terms of cloud types. J. Meteor. Soc. Japan, 92, 107-120, https://doi.org/ 10.2151/jmsj.2014-107.

Lee, S.-K., C. R. Mechoso, C. Wang, and J. D. Neelin, 2013: Interhemispheric influence of the northern summer monsoons on southern subtropical anticyclones. J. Climate, 26, $10193-$ 10 204, https://doi.org/10.1175/JCLI-D-13-00106.1.

Li, W., L. Li, M. Ting, and Y. Liu, 2012: Intensification of Northern Hemisphere subtropical highs in a warming climate. Nat. Geosci., 5, 830-834, https://doi.org/10.1038/ngeo1590.

_ Hemisphere summertime subtropical anticyclones in a warming climate. Geophys. Res. Lett., 40, 5959-5964, https:// doi.org/10.1002/2013GL058124.

Li, Y., D. W. J. Thompson, and S. Bony, 2015: The influence of atmospheric cloud radiative effects on the large-scale atmospheric circulation. J. Climate, 28, 7263-7278, https://doi.org/ 10.1175/JCLI-D-14-00825.1.

,-- , and Y. Huang, 2017: The influence of atmospheric cloud radiative effects on the large-scale stratospheric circulation. J. Climate, 30, 5621-5635, https://doi.org/10.1175/JCLID-16-0643.1.

,-- S. Bony, and T. M. Merlis, 2019: Thermodynamic control on the poleward shift of the extratropical jet in climate change simulations: The role of rising high clouds and their radiative effects. J. Climate, 32, 917-934, https://doi.org/ 10.1175/JCLI-D-18-0417.1.

Lilly, D. K., 1968: Models of cloud-topped mixed layers under a strong inversion. Quart. J. Roy. Meteor. Soc., 94, 292-309, https://doi.org/10.1002/qj.49709440106. 
Loeb, N. G., and Coauthors, 2018: Clouds and the Earth's Radiant Energy System (CERES) Energy Balanced and Filled (EBAF) Top-of-Atmosphere (TOA) edition-4.0 data product. J. Climate, 31, 895-918, https://doi.org/10.1175/JCLI-D-17-0208.1.

Ma, C.-C., C. R. Mechoso, W. A. Robertson, and A. Arakawa, 1996: Peruvian stratus clouds and the tropical Pacific circulation: A coupled ocean-atmosphere GCM study. J. Climate, 9, 1635-1645, https://doi.org/10.1175/1520-0442(1996)009<1635: PSCATT $>2.0 . \mathrm{CO} ; 2$.

Matsuno, T., 1966: Quasi-geostrophic motions in the equatorial area. J. Meteor. Soc. Japan, 44, 25-43, https://doi.org/10.2151/ jmsj1965.44.1_25.

Merlis, T. M., 2015: Direct weakening of tropical circulations from masked $\mathrm{CO}_{2}$ radiative forcing. Proc. Natl. Acad. Sci. USA, 112, 13 167-13 171, https://doi.org/10.1073/pnas. 1508268112.

Miyamoto, A., H. Nakamura, and T. Miyasaka, 2018: Influence of the subtropical high and storm track on low-cloud fraction and its seasonality over the south Indian Ocean. J. Climate, 31, 4017-4039, https://doi.org/10.1175/JCLI-D-17-0229.1.

Miyasaka, T., and H. Nakamura, 2005: Structure and formation mechanisms of the Northern Hemisphere summertime subtropical highs. J. Climate, 18, 5046-5065, https://doi.org/ 10.1175/JCLI3599.1.

— , and - 2010: Structure and mechanisms of the Southern Hemisphere summertime subtropical anticyclones. J. Climate, 23, 2115-2130, https://doi.org/10.1175/2009JCLI3008.1.

Morioka, Y., T. Tozuka, and T. Yamagata, 2010: Climate variability in the southern Indian Ocean as revealed by selforganizing maps. Climate Dyn., 35, 1059-1072, https://doi.org/ 10.1007/s00382-010-0843-x.

Myers, T. A., and J. R. Norris, 2016: Reducing the uncertainty in subtropical cloud feedback. Geophys. Res. Lett., 43, 21442148, https://doi.org/10.1002/2015GL067416.

Nakamura, H., 2012: Future oceans under pressure. Nat. Geosci., 5, 768-769, https://doi.org/10.1038/ngeo1623.

Nam, C., S. Bony, J.-L Dufresne, and H. Chepfer, 2012: The 'too few, too bright' tropical low-cloud problem in CMIP5 models. Geophys. Res. Lett., 39, L21801, https://doi.org/10.1029/ 2012 GL053421.

Onogi, K., and Coauthors, 2007: The JRA-25 reanalysis. J. Meteor. Soc. Japan, 85, 369-432, https://doi.org/10.2151/jmsj.85.369.

Philander, S. C., H. D. Gu, D. Halpern, G. Lambert, N.-C. Lau, T. Li, and R. C. Pacanowski, 1996: Why the ITCZ is mostly north of the equator. J. Climate, 9, 2958-2972, https://doi.org/ 10.1175/1520-0442(1996)009<2958:WTIIMN>2.0.CO;2.

Qu, X., A. Hall, S. A. Klein, and P. M. Caldwell, 2014: On the spread of changes in marine low cloud cover in climate model simulations of the 21st century. Climate Dyn., 42, 2603-2626, https://doi.org/10.1007/s00382-013-1945-z.

,,--- , and A. M. DeAngelis, 2015: Positive tropical marine low-cloud cover feedback inferred from cloudcontrolling factors. Geophys. Res. Lett., 42, 7767-7775, https://doi.org/10.1002/2015GL065627.

Randall, D. A., Harshvardhan, D. A. Dazlich, and T. G. Corsetti, 1989: Interactions among radiation, convection, and largescale dynamics in a general circulation model. J. Atmos. Sci., 46, 1943-1970, https://doi.org/10.1175/1520-0469(1989)046<1943: IARCAL $>2.0 . \mathrm{CO} ; 2$.

Reynolds, R. W., N. A. Rayner, T. M. Smith, D. C. Stokes, and W. Wang, 2002: An improved in situ and satellite SST analysis for climate. J. Climate, 15, 1609-1625, https://doi.org/10.1175/ 1520-0442(2002)015<1609:AIISAS > 2.0.CO;2.
Rodwell, M. J., and B. J. Hoskins, 2001: Subtropical anticyclones and summer monsoons. J. Climate, 14, 3192-3211, https:// doi.org/10.1175/1520-0442(2001)014<3192:SAASM>2.0.CO;2.

Rossow, W. B., and R. A. Schiffer, 1991: International Satellite Cloud Climatology Project (ISCCP) cloud data products. Bull. Amer. Meteor. Soc., 72, 2-20, https://doi.org/10.1175/15200477(1991)072<0002:ICDP>2.0.CO;2.

- , and - 1999: Advances in understanding clouds from ISCCP. Bull. Amer. Meteor. Soc., 80, 2261-2288, https:// doi.org/10.1175/1520-0477(1999)080<2261:AIUCFI>2.0.CO;2.

Schott, F. A., S.-P. Xie, and J. P. McCreary Jr., 2009: Indian Ocean circulation and climate variability. Rev. Geophys., 47, RG1002, https://doi.org/10.1029/2007RG000245.

Seager, R., R. Murtugudde, N. Naik, A. Clement, N. Gordon, and J. Miller, 2003: Air-sea interaction and the seasonal cycle of the subtropical anticyclones. J. Climate, 16, 1948-1966, https:// doi.org/10.1175/1520-0442(2003)016<1948:AIATSC>2.0.CO;2.

Shaw, T. A., and A. Voigt, 2015: Tug of war on summertime circulation between radiative forcing and sea surface warming. Nat. Geosci., 8, 560-566, https://doi.org/10.1038/ ngeo2449.

Slingo, A., and J. M. Slingo, 1988: The response of a general circulation model to cloud longwave radiative forcing. I: Introduction and initial experiments. Quart. J. Roy. Meteor. Soc., 114, 1027-1062, https://doi.org/10.1002/qj.49711448209.

- and -1991 : The response of a general circulation model to cloud longwave radiative forcing. II: Further studies. Quart. J. Roy. Meteor. Soc., 117, 333-364, https://doi.org/10.1002/ qj.49711749805.

Stevens, B., S. Bony, and M. J. Webb, 2012: Clouds On-Off Klimate Intercomparison Experiment (COOKIE). 12 pp., http://hdl. handle.net/11858/00-001M-0000-0024-580A-3.

Tozuka, T., and P. Oettli, 2018: Asymmetric cloud-shortwave radiation-sea surface temperature feedback of Ningaloo Niño/ Niña. Geophys. Res. Lett., 45, 9870-9879, https://doi.org/ 10.1029/2018GL079869.

Wang, Y., S.-P. Xie, B. Wang, and H. Xu, 2005: Large-scale atmospheric forcing by southeast Pacific boundary layer clouds: A regional model study. J. Climate, 18, 934-951, https:// doi.org/10.1175/JCLI3302.1.

Watanabe, M., and M. Kimoto, 2000: Atmosphere-ocean thermal coupling in the North Atlantic: A positive feedback. Quart. J. Roy. Meteor. Soc., 126, 3343-3369, https://doi.org/10.1002/ qj.49712657017.

—, and - 2001: Corrigendum. Quart. J. Roy. Meteor. Soc., 127, 733-734, https://doi.org/10.1002/qj.49712757223.

Watt-Meyer, O., and D. M. W. Frierson, 2017: Local and remote impacts of atmospheric cloud radiative effects onto the eddydriven jet. Geophys. Res. Lett., 44, 10036-10044, https:// doi.org/10.1002/2017GL074901.

Williams, E., and N. Renno, 1993: An analysis of the conditional instability of the tropical atmosphere. Mon. Wea. Rev., 121, 21-36, https://doi.org/10.1175/1520-0493(1993)121<0021:AAOTCI> 2.0.CO;2.

Wood, R., 2012: Stratocumulus clouds. Mon. Wea. Rev., 140, $2373-$ 2423, https://doi.org/10.1175/MWR-D-11-00121.1.

— stratiform low cloud cover and lower-tropospheric stability. J. Climate, 19, 6425-6432, https://doi.org/10.1175/JCLI3988.1.

Wu, G., and Y. Liu, 2003: Summertime quadruplet heating pattern in the subtropics and the associated atmospheric circulation. Geophys. Res. Lett., 30, 1201, https://doi.org/10.1029/ 2002 GL016209. 
Xie, S.-P., and S. G. H. Philander, 1994: A coupled ocean-atmosphere model of relevance to the ITCZ in the eastern Pacific. Tellus, 46A, 340-350, https://doi.org/10.3402/tellusa.v46i4.15484.

_ , and Coauthors, 2007: A regional ocean-atmosphere model for eastern Pacific climate: Toward reducing tropical biases. J. Climate, 20, 1504-1522, https://doi.org/10.1175/JCLI4080.1.

, C. Deser, G. A. Vecchi, J. Ma, H. Teng, and A. T. Wittenberg, 2010: Global warming pattern formation: Sea surface temperature and rainfall. J. Climate, 23, 966-986, https://doi.org/10.1175/2009JCLI3329.1.

Yu, J.-Y., and C. R. Mechoso, 1999: Links between annual variations of Peruvian stratocumulus clouds and of SST in the eastern equatorial Pacific. J. Climate, 12, 3305-3318, https:// doi.org/10.1175/1520-0442(1999)012<3305:LBAVOP>2.0.CO;2.
Zelinka, M. D., T. A. Myers, D. T. McCoy, S. Po-Chedley, P. M. Caldwell, and P. Ceppi, 2020: Causes of higher climate sensitivity in CMIP6 models. Geophys. Res. Lett., 47, e2019GL085782, https://doi.org/10.1002/2015GL067416.

Zhang, M. H., and Coauthors, 2005: Comparing clouds and their seasonal variations in 10 atmospheric general circulation models with satellite measurements. J. Geophys. Res., 110, D15S02, https://doi.org/10.1029/2004JD005021.

Zuidema, P., and Coauthors, 2016: Challenges and prospects for reducing coupled climate model SST biases in the eastern tropical Atlantic and Pacific Oceans: The U.S. CLIVAR Eastern Tropical Oceans Synthesis Working Group. Bull. Amer. Meteor. Soc., 97, 2305-2328, https://doi.org/10.1175/ BAMS-D-15-00274.1. 